\title{
Trial and Error: Drugs and the Treatment of Infectious Diseases
}

'Idiot: he should try, not talk!' In a rather unusual outburst of emotion, Schweitzer added these words in red pencil on a letter written to him by Dr. Heinz Barasch in Lambaréné in November 1936. The German physician had described his experiences with a novel combination of drugs that Schweitzer had proposed for the treatment of dysentery. Schweitzer apparently was unsatisfied with Barasch's initial reluctance to perform the new therapy, the way that he had eventually carried it out, and the results that it had generated.

This anecdote illustrates the pressure felt by doctors at the Albert Schweitzer Hospital to continually test new medication for the treatment of infectious diseases. Many examples of this 'trial and error' approach, as I will henceforth term it, are to be found in the sources. The regular execution of such testing suggests that Schweitzer and his doctors often doubted the usefulness of standard medicines and contradicts the optimism they displayed in public and private communications about many of these drugs.

The pharmaceutical treatment of dysentery, which has received very little attention from historians, and leprosy, which is very well researched, illustrate a central part of the daily clinical work in an institution that was primarily curative. ${ }^{2}$ Doctors were constantly confronted with the question which one of the numerous drugs at their disposal they should give to a patient. They thus tested their suitability concerning efficacy, side effects, and dosage form and hence embraced an experimental approach to medicine. Historians have often used the metaphor of the laboratory or the experiment to describe such processes for a range of large-scale scientific and medical projects in Africa and beyond. My findings about daily practices in a small-scale and curative institution demonstrate that medicine works in a similar manner on a much more basic level.

1 Barasch to Schweitzer, 24 November 1936, AMs.

2 I have selected illnesses whose treatments can be easily traced throughout the study period. Syphilis and gonorrhea were also widespread, but sources are more silent on these diseases, as is true for malaria. Patients suffering from sleeping sickness were sent to government facilities from the mid-1930s. Tuberculosis became a major concern only after the hospital acquired X-ray equipment in 1954. Ulcers are discussed in: Mabika Ognandzi, Steinke, and Zumthurm, Schweitzer's Lambaréné: A Hospital in Colonial Africa. 


\section{Experiments in a Laboratory? the Treatment of Leprosy in Colonial Africa}

Specialists at the first world leprosy conference in 1897 in Berlin concluded that complete isolation would represent the best form of treatment for patients with the disease. Colonial governments often ignored this recommendation for financial reasons. ${ }^{3}$ In German territories, officials did not compel leprosy sufferers to isolate themselves. In most German-run leproseries, which were established in the period around 1910, patients were expected to perform agricultural work to guarantee the self-sufficiency of these facilities. ${ }^{4}$ The most frequented German institutions lay in East Africa. These camps, which operated in partnership with missions, accommodated patients' non-affected family members. ${ }^{5}$

British colonial authorities established a number of leprosy settlements of their own in the late 1920 and early 1930s, such as in Uganda or Nigeria. ${ }^{6}$ These were usually segregated, for example according to ethnicity, marital status, or stage of illness. Patients were also made to perform agricultural labor. Many of these settlements were conceived as 'native villages', not only architectonically, but also in terms of their hierarchical social structures. ${ }^{7}$ For Megan Vaughan, the 'practices of twentieth-century sanitoria $($ for $T B)$ in Britain make some of the African leper colonies look like holiday camps', since the enforcement of rules was not particularly strict in the latter. ${ }^{8}$

In French West Africa, conditions in early-twentieth-century leproseries were reported to be unsanitary, resembling 'more a prison for life than a health center.' ${ }^{9}$ According to Eric Silla, colonial officials came to realize during the 1920 s that 'treating patients more or less as criminals frightened them away from medical treatment'. ${ }^{10}$ The open leprosery in Bamako, which provided food, accommodation, and agricultural land, was established in 1932. In the

3 Bado, Médecine coloniale et grandes endémies en Afrique, 141-42; Watts, Epidemics and History, 68.

4 Eckart, Medizin und Kolonialimperialismus. Camps in Togo and Cameroon had very limited success in terms of treatment; see 152-60, 210-14.

5 Ibid., 32-33. Members of the British Universities' Mission to Central Africa (UMCA) who took over the running of the settlement on the shores of Lake Malawi were horrified at the conditions they found there. See: Good, The Steamer Parish, 338.

6 Manton, 'Mission, Clinic, and Laboratory', 319; Vongsathorn, 'First and Foremost the Evangelist?', $55^{2}$.

7 Vaughan, Curing Their Ills, 89-92.

8 Ibid., 96. Italics mine.

9 Bado, Médecine coloniale et grandes endémies en Afrique, 143.

10 Silla, People Are Not the Same, 101. 
colony's new leprosy settlement system, which was designed to 'facilitate regular and prolonged treatment' instead of 'segregat(ing) the sick from the rest of the population', patient cooperation was crucial. ${ }^{11}$

Missions played a leading role in establishing many of these settlements. John Manton posits that leprosy served the relations between missionary and donor community far more than it informed evangelical strategies in Africa.' ${ }^{12}$ In the process, colonial discourses were reframed. Benedictines depicted Africans suffering from leprosy as hard-working, grateful, and willing to suffer and submit to missionaries and their God. Their unafflicted counterparts, on the other hand, were presented as lazy, unappreciative, dull, and insubordinate. ${ }^{13}$

From a medical perspective, most leprosy programs had a limited reach and scope, especially during the interwar period. Any improvement in the health of leprosy patients during this period was most likely due to improved diets, sanitation, and nursing. ${ }^{14}$ Missions and governments established leprosy settlements not only out of strictly medical considerations. The camps in Uganda, for example, represented a particular 'vision for the future of Uganda as a "civilised" and Christian country'. ${ }^{15}$ In many parts of the continent, colonial governments aimed to establish closer cooperation with missions after World War Two, when the increasing availability of much more efficacious sulfone drugs allowed more and more leprosy sufferers to seek outpatient treatment. ${ }^{16}$

When Schweitzer first arrived in Lambaréné in 1913, biomedical practitioners routinely used substances extracted from the seeds of the Chaulmoogra tree to treat leprosy. Often, this was injected in the form of oil, with the shots being painful and the effects limited. ${ }^{17}$ Medical professionals in the interwar period disagreed on how best to treat the disease, with chaulmoogra oil losing and regaining favor among doctors repeatedly. ${ }^{18}$ Before 1945 , from when the newly developed sulfone drugs promised to provide a more efficacious treatment, physicians throughout Africa experimented with different preparations from this plant, ${ }^{19}$ as well as with a range of compounds varying from olive oil to

\footnotetext{
11 Ibid., 104.

12 Manton, 'Mission, Clinic, and Laboratory', 333.

13 Hölzl, 'Lepra als entangled disease', 111.

14 Vaughan, Curing Their Ills, 84. See also: Brydan, 'Mikomeseng', 637.

15 Vongsathorn, 'First and Foremost the Evangelist?', 544.

16 Manton, 'Mission, Clinic, and Laboratory', 327; Vaughan, Curing Their Ills, 90-92.

17 Digby, Diversity and Division in Medicine, 175-76; Eckart, Medizin und Kolonialimperialismus, 217; Good, The Steamer Parish, 339. The plant's latin binomial is Hydnocarpus wightignus. It is native to Southeast Asia.

18 Worboys, 'The Colonial World as Mission and Mandate'.

19 Addae, The Evolution of Modern Medicine in a Developing Country, 238; Good, The Steamer Parish, 341.
} 
iodoform, trichloroacetic acid, and potassium iodide. ${ }^{20}$ In the case of colonial Vietnam, Laurence Monnais argues that similar experiments and the perpetual replenishment of leprosy drugs by pharmaceutical companies transformed colonial health professionals' previously overriding therapeutic skepticism into a more optimistic attitude towards their ability to treat the disease. ${ }^{21}$ For his part, Schweitzer had always displayed such therapeutic optimism, not only in relation to the treatment of leprosy.

The history of the distribution of sulfones in Africa is not yet fully understood. In Bamako, first experiments with these drugs were undertaken in 1948, but chaulmoogra was still widely used in French West Africa a decade later. ${ }^{22}$ The Universities' Mission to Central Africa first made use of sulfone drugs in 1951 and soon realized that 'many new cases continued to emerge.'. ${ }^{23}$ Manton has revealed how in this context of therapeutic hope, small-scale experiments with a variety of drugs were central in research conducted at the leprosy hospital in Uzuakoli, Nigeria that led to the development of clofazimine, a medication still used today. He characterizes the scientific process of drug research at Uzuakoli as 'decentralized' and 'disarticulated', 24 insisting that 'the less than ideal physical and geographical circumstances of most leprosy research, the impossibility of cultivating leprosy outside a living human host, and the persistent privileging of local clinical knowledge' forces us to think of experimental research situations that simultaneously formed part of a treatment regime as 'characteristic rather than anomalous.' ${ }^{25}$

The situation in AEF was similar. A government report from 1955, when sulfones already constituted the standard treatment, claimed that like everywhere else in the French territories and elsewhere, many drugs have been tried'. The author concluded that, 'unfortunately, after slight improvements, not always very significant, it had to be agreed that there was no definite cure.'. ${ }^{26}$ Two years before, the director of the Service Général d'Hygiene Mobile et de Prophylaxie had distributed a guideline for leprosy treatment to all chief physicians in each sector of the colony. He recommended the exclusive use of sulfone-mère, a drug that is surprisingly never mentioned in sources relating to the Albert Schweitzer Hospital. Dapsone, as it was also known, was cheaper and, coming in the form of a pill, easier to administer than Promin and Diasone,

\footnotetext{
20 Eckart, Medizin und Kolonialimperialismus, 214-17, 337-39; Good, The Steamer Parish, 341.

21 Monnais, Médicaments coloniaux, 89-91.

22 Silla, People Are Not the Same, 107-10.

23 Good, The Steamer Parish, 344.

24 Manton, 'Trialing Drugs, Creating Publics', 87.

25 Ibid., 94-95.

26 Cheneveau, 'La lutte contre la lèpre en A.E.F', 1955, PR(H), 1 H 254.1. ANG, 1.
} 
which had been the preferred drugs of doctors in AEF from 1941 to $1948 .{ }^{27}$ Even though these government specialists attempted to unify and standardize treatment, they conceded that there were a great variety of possible medications, the potential efficacy of which depended on the local context as well as the condition and preferences of the patient and the views of the doctor. ${ }^{28}$

The 'laboratory' seems to be a useful metaphor for describing such experimental processes in science at large, ${ }^{29}$ especially those in colonial contexts, drawing our attention 'to the prominence of scientific, notably, medical, research in imaginaries of Africa and, at the same time, to the tentative, exploratory nature, and often failure' of many research programs. ${ }^{30}$ However, as a mere metaphor, indeed one that was invoked by colonialists themselves, ${ }^{31}$ this analogy is not without its weaknesses, as Guillaume Lachenal highlights: 'the colonial opportunity gave rise to extraordinarily ambitious health policies, whose brutality and racism had absolutely nothing metaphorical about them.' ${ }^{32}$ The other argument against using this comparison is that, unlike in a laboratory, conditions in the colonies were usually beyond the control of experimenters and, as such, not artificially created for the purposes of their experiments. ${ }^{33}$

Social and historical scholars of science have also frequently evoked metaphors around the term 'experiment' to examine scientific processes in laboratories and beyond. ${ }^{34}$ Studies by Christoph Bonneuil and Helen Tilley emphasize the interdisciplinary and cooperative nature of the experiments that took place in the colonial 'laboratory' of Africa. ${ }^{35}$ Furthermore, their work demonstrates how difficult it is to differentiate between the two metaphors of the laboratory and the experiment; these are often presented as interchangeable concepts in historical writing.

27 Richet, 'Lèpre. - Instructions, dépistages, traitements, pensions, statistiques', 1953, PR(H), $1 \mathrm{H}$ 254.4. ANG, 2.

28 Cheneveau, 'La lutte contre la lèpre en A.E.F', 1955, PR(H), 1 H 254.1. ANG, 7-8; Richet, 'Lèpre. - Instructions, dépistages, traitements, pensions, statistiques', 1953, PR(H), 1 H 254.4. ANG, 6.

29 Knorr-Cetina, Wissenskulturen, 45.

30 Geissler, 'Public Secrets in Public Health', 13-14.

31 Bonneuil, 'Development as Experiment', 259; Tilley, Africa as a Living Laboratory, 5 .

32 Lachenal, 'Le médecin qui voulut être roi', 128. Following Foucault, Lachenal suggests viewing the colonies as both real and imagined 'counter-emplacements' of the metropole.

33 Stoler and Cooper, 'Between Metropole and Colony', 5 .

34 Knorr-Cetina, Wissenskulturen, 45. Dirk van Laak for instance proposes the term 'Experminetierfeld'. Van Laak, 'Kolonien als “Laboratorien der Moderne?"', 258-59. A recent example: Moore-Sheeley, 'The Products of Experiment'.

Tilley, Africa as a Living Laboratory, 27; Bonneuil, 'Development as Experiment', 264. 
Recent studies on medical research in Africa focus on the experimental dimension in the testing of pharmaceutical and non-pharmaceutical therapies alike. They reach the conclusion that participants in research trials believed that they were part of a large-scale treatment program. ${ }^{36}$ In fact, therapy and experiment were often conducted simultaneously, not only for leprosy. Both Lachenal and Wolfgang Eckart, the latter invoking the laboratory metaphor, have demonstrated for different periods and contexts how trial-and-error methods were used not only to determine a drug's efficacy in humans, but also as a means of treating the patients who participated in these very trials. ${ }^{37}$

Given that the first international guidelines on medical research on humans were loosely formulated in the Nuremberg Code of 1947 and more precisely in the Declaration of Helsinki in 1964, it is unsurprising, but nevertheless important to highlight, that the occurrence of such 'therapeutic experiments' was not limited to the colonies, ${ }^{38}$ nor were they restricted to the pharmaceutical domain. 'Learning from mistakes' was the preferred approach adopted by early-twentieth-century surgeons to improve their skills. ${ }^{39} \mathrm{~A}$ broad survey of the practices of German-speaking doctors in the nineteenth century has also revealed how highly this cohort valued personal experience and empirical knowledge over laboratory results and information derived from textbooks. ${ }^{40}$

While the central role played by hospital doctors in conducting pharmaceutical tests in colonial Southeast Asia, notably for dysentery drugs, is undisputed, ${ }^{41}$ this issue has not been explored in detail for Africa. Medical research facilities on the continent were often attached to hospitals, ${ }^{42}$ but it is not clear what role the latter played in experiments. Similarly, the function of experiments in hospitals that conducted their own research, ${ }^{43}$ or in the

36 Graboyes, The Experiment Must Continue, 45; Malloy, 'Research Material and Necromancy', 435 .

37 Eckart, 'The Colony as Laboratory', 202; Lachenal, Le médicament qui devait sauver l'Afrique.

38 Hess, Hottenrott, and Steinkamp, Testen im Osten; Marks, The Progress of Experiment, 159-62; Meier et al., Testfall Münsterlingen.

39 Wilde and Hirst, 'Learning from Mistakes'.

40 Kinzelbach, Neuner, and Nolte, 'Medicine in Practice: Knowledge, Diagnosis and Therapy'.

41 Gouda, 'Mimicry and Projection in the Colonial Encounter'; Monnais, Médicaments coloniaux, 124-30.

42 This was the case for the Wellcome Tropical Research Laboratories in Khartoum, founded in 1903, or the Pasteur Institute, opened in Yaoundé in 1959. See: Bell, Frontiers of Medicine, 88f; Lachenal, 'Franco-African Familiarities', 422.

43 This was the case, for instance, in Makere and Nairobi. See: Iliffe, East African Doctors, 174 f. 
numerous mission hospitals that were, like the Albert Schweitzer Hospital, run mainly as curative institutions, is also not evident.

Isgard Ohls has already observed how well Schweitzer's hospital, and especially its leprosy settlement, might reflect these experimental patterns. She writes of a twofold 'experimental field', one for the experimental development of new therapies and the second for 'practical training into the ethics of reverence for life in the clinical everyday life of the leprosy village'.44 Ruth Harris terms the hospital a 'colony within a colony', ${ }^{45}$ which would thereby render the leprosy settlement a colony within a colony within a colony. These images are useful when conceiving of the hospital, the leprosy village, or both as a laboratory for Schweitzer's ethics, as suggested in the Introduction. They are less accurate when describing the hospital's pharmaceutical treatment of dysentery and leprosy patients. For these small-scale tests, the results of which were intended only for internal use as guidelines for present and future physicians, I prefer the term 'trial and error'.

\section{Leprosy in Lambaréné}

According to Rita Headrick, leprosy was 'virtually ignored' in AEF, which is surprising in view of the significant efforts to combat the disease in other French colonies. ${ }^{46}$ Still, the colonial government ran at least eight 'leprosy villages or agricultural settlements' in Gabon during the interwar period, ${ }^{47}$ including a comparatively large settlement in Lambaréné. In 1936, Dr. Ladislav Goldschmid expressed doubt that conditions in this camp were adequate. He had heard that 'no fewer than 100 of $[\ldots] 140$ lepers fled the camp. That says a lot, if it is true., ${ }^{48}$ Later that year, the government physician in Lambaréné and his superior from Brazzaville inspected Schweitzer's hospital and ordered that leprosy and sleeping sickness patients be sent to government facilities. Although 'quite a few' leprosy patients continued to seek treatment and shelter at the Albert Schweitzer Hospital after this inspection, Goldschmid sent them to the government's institution. This was not only 'because of formality', but also because he feared that in their increasing numbers leprosy patients would take up too much space. ${ }^{49}$ Reports of the suffering of leprosy patients at the government

44 Ohls, Der Arzt Albert Schweitzer, 165.

45 Harris, 'Schweitzer and Africa', 1127.

46 Headrick, Colonialism, Health and Illness in French Equatorial Africa, 163.

47 Mabika, 'Médicalisation de l'Afrique centrale', 321.

48 Goldschmid to Schweitzer, 16 July 1936, AMs.

49 Goldschmid to Schweitzer, 24 October 1936, AMs. 


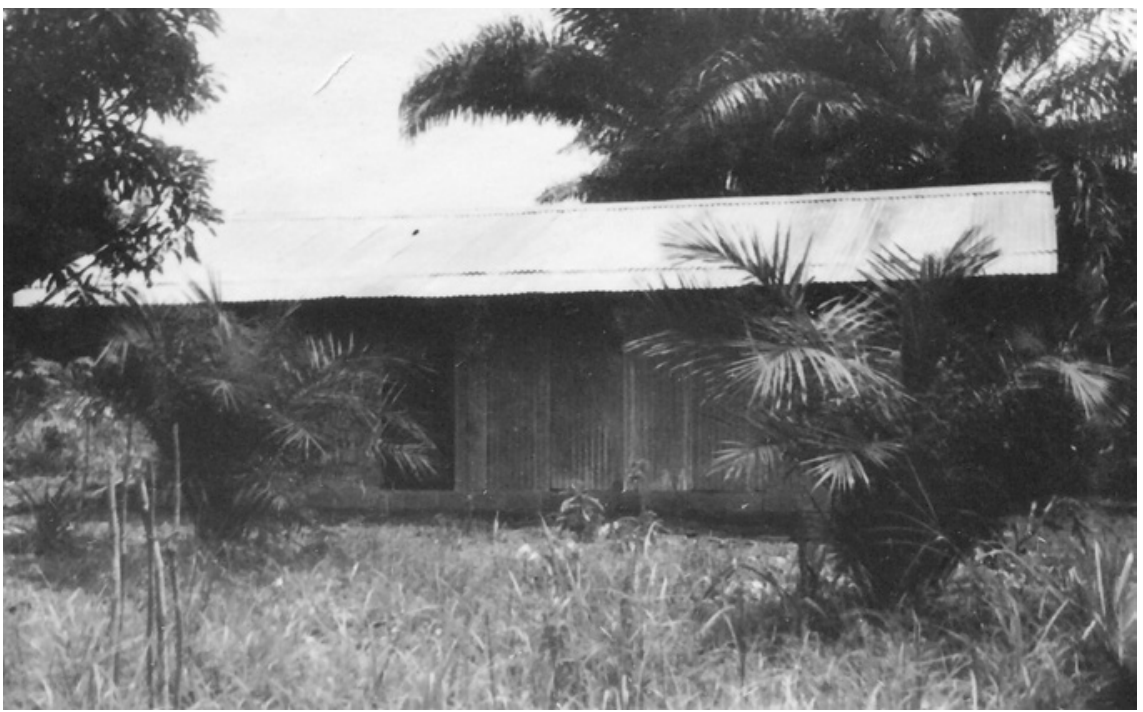

ILLUSTRATION 28 The hospital's isolation hut, away from the main buildings on a forest clearing, early 1930 s

(C) ARCHives CENTRALES ALBERT SCHWEITZER GUNSBACH

institution in Lambaréné, however, left him concerned. They 'tell us that they are not treated, not bandaged, they hardly get anything to eat and moreover they are maltreated with beatings' 50

It is difficult to verify these accusations; Goldschmid did hold a certain degree of resentment towards his colleague and rival from the nearby government facility, but his claims do reflect some of the findings of scholars who have examined the history of African leprosy settlements in the early twentieth century. Despite these allegations of maltreatment, patients with leprosy were sent to the sanitary formation of the government for the following two years. ${ }^{51}$ This arrangement remained in place for sleeping sickness patients for the rest of the study period, but was to be revoked for those affected by leprosy during World War Two.

The first steps towards establishing a leprosy settlement at the Albert Schweitzer Hospital were taken in 1930, when an isolation ward was built (see Illustration 28). ${ }^{52}$ During the 1930s, an average of approximately forty leprosy patients were treated at the hospital per year. In August 1936, when sixteen

5o Ibid.

$5^{1}$ See the 'Statistiques de l'Hôpital' for 1937 and 1938, L - A - S3, AMs.

52 Woytt-Secretan, Albert Schweitzer baut Lambarene, 78. 
leprosy sufferers were present, two rooms had to be cleared in the ward designated for tuberculosis patients. ${ }^{53}$ The hospital staff's main motivation for segregating leprosy patients was to prevent the spread of the infection through the institution. It was also necessary to keep patients at the hospital to undergo long-term treatment with chaulmoogra drugs. Dr. Anna Wildikann, who was not sure how long they had to keep patients, raised doubts about this 'asylum policy' in 1935. The problem was that 'when they get bored, they just run away or - like some others do at the moment - they constantly revolt'.54 As we will see below, patients did not like taking compounds from chaulmoogra, while doctors tried to find ways to make their application less unpleasant.

In the mid-195os, the Service Général d'Hygiene Mobile et de Prophylaxie attempted to calculate the number of people affected by leprosy in AEF and to determine treatment for each patient..$^{55}$ By the end of the decade, almost 9,688 leprosy sufferers had been counted in Gabon. ${ }^{56}$ This colonial effort was modelled on the successful campaigns against sleeping sickness orchestrated by Eugène Jamot in the early 1930s, in which mobile teams had distributed pills and administered injections. These programs were admired by colonial doctors because "this "simple, efficacious" approach minimized the disturbances in the patient's life and permitted the complete avoidance of "segregation" and "detribalisation". 57

The development of leprosy settlements in Gabon illustrates the shift away from isolation as the preferred means of treating the disease. In 1943, the colonial administration maintained ten leproseries in Gabon, ${ }^{58}$ including one in Lambaréné with forty beds. ${ }^{59}$ Ten years later, the eleven government 'leper colonies' provided a total of 930 beds. ${ }^{60}$ French officials had envisaged establishing villages 'like the others' that would enjoy maximal autonomy and self-sufficiency, but this plan was not realized due to financial restrictions

53 Goldschmid to Schweitzer, 11 August 1936, AMs.

54 Wildikann to Schweitzer, 15 December 1935, AMs.

55 Mabika lists the following possible treatments: 'oral, intravenous, at home, at the treatment centre, in the leprosy community, in hospital'. Mabika, 'Médicalisation de l'Afrique centrale', 219.

56 Ibid.

57 Silla, People Are Not the Same, 109-10. See also: Bado, Médecine coloniale et grandes endémies en Afrique, 359-6o.

$5^{8}$ 'Projet de Réorganisation du Service de l'A.M.I', dated 15 January 1944 compiled by Médecin-Colonel Bizien, Inspecteur Général des Services Sanitaires et Médicaux de l'A.E.F., 117, ZK 005-127, SHD.

59 'Rapport Annuel du Service de Santé de la Colonie du Gabon 1945', ZK 005-005, SHD.

6o Mabika, 'Médicalisation de l'Afrique centrale', 322. 
and because the 'displacement' of patients was not considered to be 'ideal'.61 In 1950, 1,185 leprosy patients lived in the government settlements of AEF, while another 3,757 underwent outpatient treatment. ${ }^{62}$ Schweitzer's hospital, on the other hand, treated 204 leprosy patients, of which 146 were hospitalized. ${ }^{63}$ In 1954, the Lambaréné government hospital recorded a total of 50 inpatients and 84 outpatients with leprosy, ${ }^{64}$ whereas Schweitzer's newly established 'village des lumières', as this settlement became known, then accommodated 250 patients. ${ }^{65}$ In 1961, 857 individuals with the disease were registered in Lambaréné District. ${ }^{66}$ At this time, about one hundred patients and approximately eighty of their family members lived in Schweitzer's leprosy settlement. 67

In 1951, Dr. Jean-Pierre Naegele provided a detailed report on the state of leprosy care at the Albert Schweitzer Hospital. ${ }^{68}$ The number of leprosy patients had quadrupled between April 1950, when large quantities of sulfones had first been provided to the hospital, and September $1951 .{ }^{69}$ People seeking leprosy treatment and their relatives had built four small settlements around the isolation ward (see Illustration 29). They were segregated according to ethnic groups and housed a total of more than 300 patients. Naegele commented that 'apparently, this is the kind of accommodation preferred by our patients. They feel at ease and send for their sick relatives from far away to join them: ${ }^{70}$ In agreement with other specialists as well as his predecessor, Dr. Wildikann, Naegele emphasized that forced isolation was not a viable approach and that

61 Cheneveau, 'La lutte contre la lèpre en A.E.F', PR(H), 1 H 254.1. ANG, 10-13.

62 'Rapport Annuel du Service de Santé de l'Afrique Equtoriale Française 1950', ZK 005-91, SHD.

63 Naegele, 'Traitement des malades lépreux à l'Hôpital du Docteur Albert Schweitzer à Lambaréné au cours de l'année 1950', AMs, 8.

64 'Rapport Annuel Des Services Sanitaires de Lambaréné 1954'. 2 DC(I) 44.11, ANG.

65 Schweitzer, 'Briefe aus dem Lambarenespital Oktober 1954'.

66 'Rapport Annuel du Centre Médical de Lambaréné 1961', 1 H 226.1, ANG.

67 Goldwyn, 'Diary 1960', AMs, 31.

68 Naegele, 'Streiflichter aus Lambarene. 1951 III. Um die Lepra', AMs.

69 The number of leprosy patients can be accurately discerned from the appels mensuels, see $\mathrm{L}-\mathrm{P}$ - AM7, AMs.

70 Fang patients, who had built their own houses, named their settlement 'Bingoung', which Naegele translated as 'tin roof'. Adouma, Bagota, Shake and other groups from the interior called their settlement of approximately thirty houses 'Bise-bouko-libengo', translated as 'we are near the hole' because of a nearby well, that had been recently dug. Bapounou, Eshira, and Mitsogo lived on a nearby hill and called their settlement 'Labilila', which according to Naegele meant either 'far view' or 'to wait'. Members of a few local minority groups had started to build a fourth settlement. See: Naegele, 'Streiflichter aus Lambarene. 1951 III. Um die Lepra', AMs, 2. 


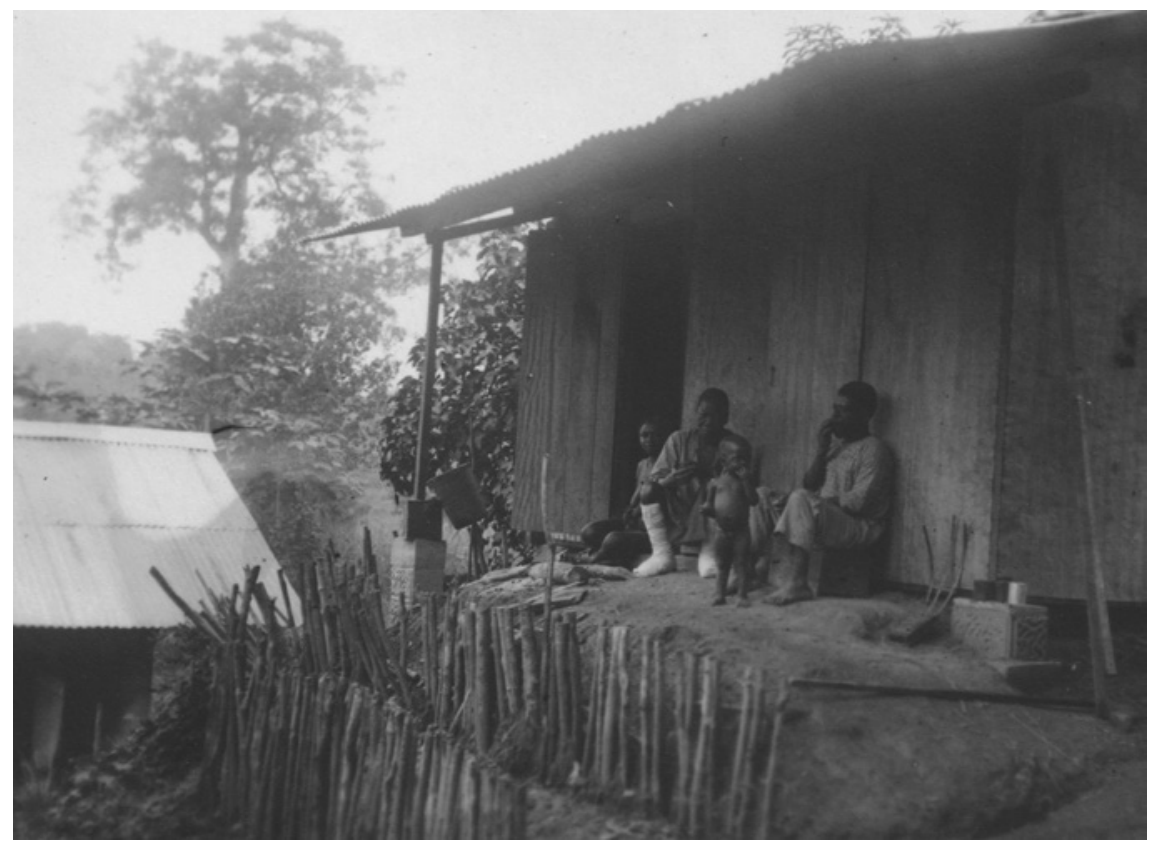

ILLUSTRATION 29 One of the huts in the first leprosy settlements, ca. $195^{\circ}$

(C) ARCHIVES CENTRALES ALBERT SCHWEITZER GUNSBACH

family members should be permitted to stay with their sick relatives in order to increase patients' willingness to remain at the hospital:

It is needless to ask if one should send the healthy relatives of lepers back home or have them stay. If we send away the healthy wife, husband or daughter, we can be sure that the night after, the patient also disappears. ${ }^{71}$

In May 1952, Schweitzer proposed rebuilding the area where these settlements had developed, ${ }^{72}$ plans that were realized one year later. The hill was flattened, and the bamboo cabins were replaced with buildings with concrete foundations, thereby creating what Schweitzer conceived of as a model village (see Illustration 3o). ${ }^{73}$ This went against the trend of decentralized outpatient treatment that was becoming standard in French colonies at the time and which was also the official approach of the colonial government in Gabon. In part, it also went against the recommendations of Schweitzer's

\footnotetext{
71 Ibid., 5 .

72 Haussknecht to Royden, 1 May 1952, AMs.

73 Schweitzer, 'Briefe aus dem Lambarenespital Oktober 1954', 6-10.
} 


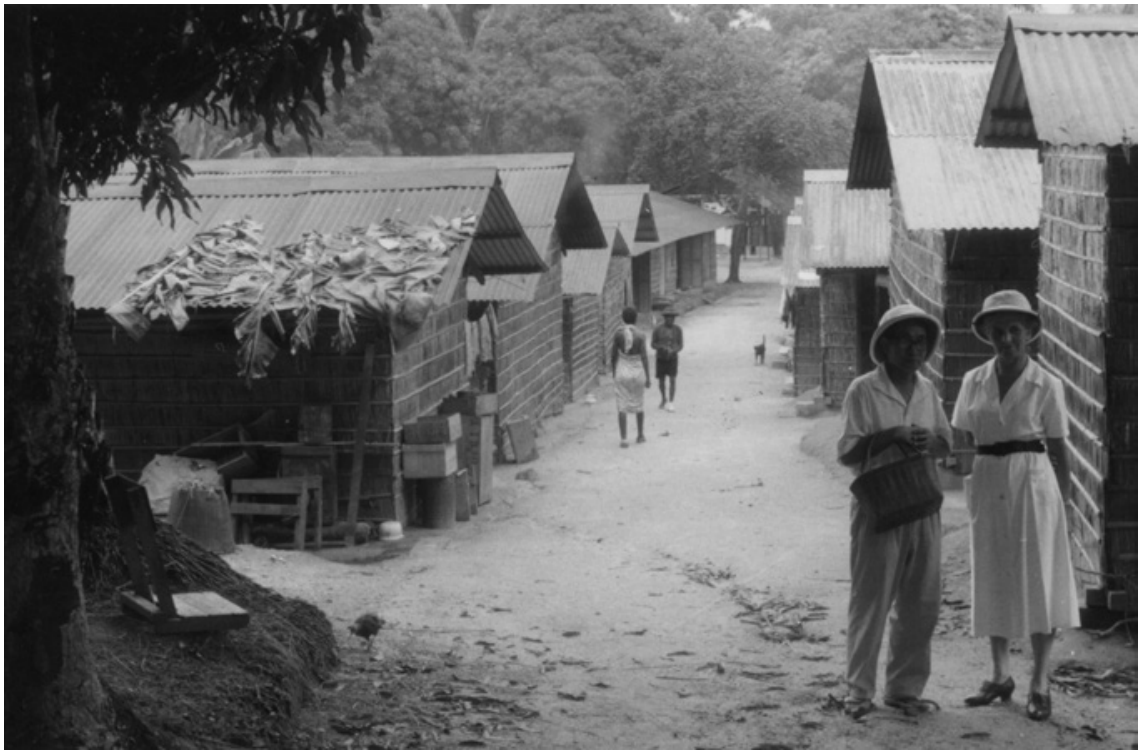

ILLUSTRATION 30 Long-serving Japanese doctor Isao Takahashi and Emmy Martin in the hospital's new leprosy settlement, the 'village lumière', ca. 1960 (C) ARChives CENTRALES ALBERT SCHWEITZER GUNSBACH

doctors and the preferences of Gabonese leprosy sufferers who sought care at the hospital. Their numbers decreased by as many as 100 patients after the opening of this new settlement for 250 people in early $1954 \cdot{ }^{74}$ By this time the government had counted all leprosy cases in the colony during the course of the above-mentioned campaign; Schweitzer's hospital had treated 649 leprosy patients since 1946. Only one-third of these patients came from the District of Lambaréné, ${ }^{75}$ which suggests that medication was not widely available elsewhere. Despite the overwhelmingly positive reputation this part of the hospital still enjoys in Europe, ${ }^{76}$ we know very little about the patients who were treated there.

African societies confronted leprosy in different ways. In some locations, affected individuals were isolated among themselves; in others, they were not

74 In September 1951, 35 o leprosy patients were documented in the appels mensuels, L - P AM1, AMs. One year later, Schweitzer even mentioned 400. See: Schweitzer and Mellon, Brothers in Spirit, 25-26. In the month in which construction of the 'village lumières' began, Schweitzer still reported the presence of 300 leprosy patients. See: Schweitzer to Stoll, 18 May 1953, AMs.

75 'Hôpital Schweitzer - Lépreux recencés depuis 1947'. PR(H), 1 H 235·3, ANG.

76 Isgard Ohls quotes numerous contemporary sources and also assesses the leprosy village in a very positive manner. See: Ohls, Der Arzt Albert Schweitzer, 171-83. 
stigmatized at all. ${ }^{77}$ This wide range of responses to the disease - from complete isolation to partial marginalization with family visits allowed to no segregation at all - could be observed even within a relatively small territory. ${ }^{78}$ It has been suggested that colonial segregation measures increased the general fear of the disease in societies where similar approaches had not been practiced before. ${ }^{79}$

In AEF in the mid-195os, some colonial officials claimed that leprosy sufferers continued to work and were not considered a burden by their fellow villagers. $^{80}$ This view shaped the French preference for decentralized treatment. At the Albert Schweitzer Hospital, where a large leprosy settlement with an international reputation was about to be created, most staff believed that Gabonese leprosy sufferers were marginalized. ${ }^{81}$ Augustin Emane's interviewees claim that leprosy patients would not only come to the hospital to be cured, but also for a place to stay after being ostracized from their villages. ${ }^{82}$ Schweitzer, however, does not appear to have made this claim himself. Dr. Naegele, who was the first doctor at the hospital to make large-scale use of sulfones, agreed with government officials in favoring ambulant treatment in the short term. He claimed that 'the lepers of the Gabon are not rejected at all by their families and are therefore not forced to seek refuge in leper settlements and stay there if they do not like it'.83 Similar discrepancies between public claims and personal correspondence have been observed in the previous chapter in the case of obstetrical emergencies. Since the treatment of leprosy was important for maintaining potentially lucrative relationships with the donor community, as argued by Manton above, Schweitzer was probably motivated to establish the settlement more by reasons other than strict medical imperatives.

Leprosy was a considerable concern among Gabonese communities. In their 1961 book on useful plants in Gabon, Raponda-Walker and Sillans list seven local plants used to treat the disease. For some of these plants, leprosy is the only indication listed, but specific details on how they were used to treat

77 Notably, the latter approach was considered less 'civilised' by European observers in the interwar period. See: Vaughan, Curing Their Ills, 80.

78 Bado, Médecine coloniale et grandes endémies en Afrique, 146; Eckart, Medizin und Kolonialimperialismus, 321.

79 Manton, 'Mission, Clinic, and Laboratory', 323.

8o Cheneveau, 'La lutte contre la lèpre en A.E.F', 1955, PR(H), 1 H 254.1. ANG, 8-9.

81 Ohls, Der Arzt Albert Schweitzer, 173.

82 Emane, Docteur Schweitzer: une icône africaine, 2013, 203-4.

83 Naegele, 'Streiflichter aus Lambarene. 1951 III. Um die Lepra', AMs, 2. 
the illness are not provided. ${ }^{84}$ Most, however, were also recommended for a variety of other dermatological afflictions. The leaves and bark of the cashew tree were used for general skin care; its nuts provided oil for external application on ulcers and leprosy wounds. ${ }^{85}$ Various plants were also used to cicatrize wounds. ${ }^{86}$ It remains unclear how many of those plants were actually in widespread use; even less certain is how many relevant medicinal plants the authors did not list at all. They also included applications known from other contexts. In relation to Caloncoba welwitschii, for example, they wrote that 'the grains are very rich in chaulmoogric oils, highly praised for curing leprosy. But this property is not known to Blacks in Gabon.' ${ }^{87}$ The local preference for using externally applied substances to treat skin afflictions found its equivalent at the Albert Schweitzer Hospital in the treatment of ulcers, including those caused by leprosy, with ointments. Sometimes made in the hospital's little pharmacy by nurses, these were used throughout the study period. ${ }^{88}$

Medical practitioners at the Albert Schweitzer Hospital had to respond to this local context when treating leprosy. They reacted to the complexity of the infection, the lack of efficacious treatments, and the sudden influx of patients by testing drugs using a trial-and-error approach. At the same time, these drugs also helped to shape this very context. Their availability enabled new types of leprosy settlements to be established, new therapeutic hope to flourish, more patients to seek treatment, and more difficult cases to be discovered. In turn, these developments shaped doctors' attitudes towards leprosy drugs and the disease itself.

84 This is the case for Culcasia, ('the leaves act against leprosy', 95) or Drymaria cordatia ('this herb is used to cure leprosy', 120) Raponda-Walker and Sillans, Les plantes utiles du Gabon.

85 Latin binomial: Anacardium occidentale. Ibid., 57.

86 For example, Gabonese Mint (Ocimum viride), ibid. 312; Leadwort (Plumbago Zeylanica), ibid. 349 .

87 Raponda-Walker and Sillans, Les plantes utiles du Gabon, 181. The The Kew Species Profiles, describe the plant as follows: 'Uses: Caloncoba welwitschii has a wide range of traditional medicinal uses in Central Africa. For example, the leaves and bark are used for treating rheumatism, and are made into poultices for applying to abscesses. The leaf-sap is used to treat headaches, and the plant itself is prescribed as a means of killing body-lice. The fruit pulp is eaten in Gabon. It has been reported that the seed oil is used to treat leprosy in the Democratic Republic of Congo'. http://powo.science.kew.org/taxon/urn:lsid:ipni. org:names:365023-1\#source-KSP (2 June 2020).

88 In 1937, Schweitzer explained to a former nurse that honey and cod liver oil were now used at the hospital for producing the ointments. See: Schweitzer to Stalder, 7 April 1937, AMs; Goldwyn mentioned 'liver paste, zinc oxide, Mercurochrome, and methylene blue'. Goldwyn, 'Diary 1960', AMs, 56. 
Dysentery in Africa has received much less historiographical attention than leprosy. It is linked with labor migration and unsanitary conditions, ${ }^{89}$ frequently occurring at railway construction sites, on plantations, or along trade routes. Unlike leprosy, it often affected Europeans, ${ }^{90}$ who typically blamed Africans for its spread by being ignorant of or unable to adapt to hygienic practices, such as using latrines. ${ }^{91}$ Today, the main advice for avoiding contracting dysentery, which is considered highly contagious, remains to habitually wash hands and foodstuffs. Both its bacillary and its amoebic form, the latter being the main focus of this chapter, are believed to pass through fecal matter or contaminated food and water. ${ }^{92}$

Rita Headrick has described government measures taken during a series of dysentery epidemics in the early 1920 along construction sites of the CongoOcean Railway, where an estimated 20 percent of the population died of the disease. Colonial officials threatened local chiefs with imprisonment or fines if they failed to report cases. Infected individuals were quarantined, while canoes were confiscated and roadblocks erected to hinder the spread of the disease. Three of the eight doctors in AEF were called to the region. Headrick argues that these 'measures added up to an energetic and expensive response to the epidemic, rather uncharacteristic of the administration, ${ }^{93}$ a sign of the priority given to the rapid construction of the railway.

Some French colonial medical officials believed that dysentery was unavoidable - an act of God, essentially - while others claimed that laborers could somehow acquire partial immunity. Colonial employers tried to avoid recruiting workers from distant areas where the disease was not endemic. They believed that these individuals would be more susceptible to the illness, having been weakened by a long journey and not being accustomed to the food served on construction sites. As dysentery came in two forms, difficulties in diagnosis added to the confusion as other intestinal parasites could provoke similar symptoms or cause simultaneous infections. ${ }^{94}$

\footnotetext{
89 Doyle, Before HIV, 97-98.

$90 \quad$ Good, The Steamer Parish, 333; Eckart, Medizin und Kolonialimperialismus, 232-33.

91 Eckart, Medizin und Kolonialimperialismus, 352-53; Headrick, Colonialism, Health and Illness in French Equatorial Africa, 167.

92 Marie and Petri Jr., 'Amoebic Dysentery'. See also: https://www.nhs.uk/conditions/dysentery/ (2 June 2020).

93 Headrick, Colonialism, Health and Illness in French Equatorial Africa, 165-67.

94 Ibid., 185-86.
} 
The few historical studies that comment on the amoebic form of the disease mention emetine hydrochloride, made from the ipecacuanha root native to Central and South America, as the treatment that was preferred by colonial doctors in the period from 1920 to 1950. Accidents due to the compound's toxicity occurred repeatedly, but alternatives, such as Stovarsol, were not without their own problems. ${ }^{95}$ It was hence recommended administering emetine via intravenous injections, which promised to be less painful than intramuscular ones, but underlined the need to closely monitor patients for potential side effects. ${ }^{96}$

It is no surprise that the crowded lumber camps in the region surrounding Lambaréné, that placed little emphasis on sanitation or balanced diets, provided an environment prone to the spread of dysentery. Indeed, RapondaWalker and Sillans list no fewer than seventeen different local plants for treating the illness in their book. Once again, it remains unclear to what extent the authors incorporated their own knowledge about these plants into their descriptions. On water cabbage leaves, for example, they wrote that 'mixed with rice and coconut milk, they can be used against dysentery, but in Gabon these uses are ignored. ${ }^{97}$ According to Raponda-Walker and Sillans, different parts of a single plant often offered different medicinal uses. After being cooked before it ripened, soursop fruit was dried and then powdered to serve as a medication for dysentery; other parts of the tree were used to treat coughs and fever or as a tranquilizer or emetic. ${ }^{98}$ Various parts of the African coralwood were said to treat toothache, yaws, gonorrhea, scabies, and wounds respectively, while 'the blacks use the boiled bark with that of Saccoglottis Gabonensis in enemas to fight dysentery' ${ }^{99} \mathrm{~A}$ range of crops were said to counter dysentery, including rice, through rice water 'as drink or enema', ${ }^{100}$ and green bananas, 'grilled in ashes and into which bark rasps from wild mango or odika butter have been introduced'. ${ }^{101}$ Notable in all of these examples is how the authors emphasized the combinations of various plants and their specific means of application in the treatment of different afflictions.

As a reaction to the dangers of emetine and the highly contagious nature of dysentery, a number of coercive therapeutic practices were followed at the

95 Ibid., 166; Good, The Steamer Parish, 233; Monnais, Médicaments coloniaux, 127.

96 Craig, The Etiology, Diagnosis, and Treatment of Amebiasis.

97 Latin binomial: Pistia stratiotes. Raponda-Walker and Sillans, Les plantes utiles du Gabon, 96 .

98 Annona muricata. Ibid., 63.

99 Pterocarpus soyauxii. Ibid., 259.

$100 \quad$ Ibid., 191.

101 Ibid., 304. 
Albert Schweitzer Hospital. When the hospital was located at its original site, dysentery patients were isolated in a building that was 'some sort of prison where we lock up the biggest banana thieves who loot Keller's beautiful plantations.'102 Writing at the hospital's new location, Dr. Ilse Schnabel noted in her diary in 1929 that the 'the dysentery patients ask why they're kept locked up like prisoners'. ${ }^{103}$ She also reported that they often escaped. The hospital's solution was to paint a blue sign onto each dysentery patient's forehead. ${ }^{104}$ Two years later, dysentery patients were placed in an isolation ward that Schweitzer described as a 'spacious, airy barrack and a barred yard', which had formerly accommodated mentally ill patients. ${ }^{105}$ Some patients attempted to hide their dysenteric symptoms in an effort to avoid being sent into isolation there. ${ }^{106}$ This ward was still operational in $1948,{ }^{107}$ but was not mentioned in the sources thereafter. References to the disease are rarer after 1950, by which time emetine's negative side effects had been reduced and efficacious alternatives had become available.

On the one hand, coercive measures were justified with reference to the need to supervise patients' diets in order to minimize the negative side effects of treatment. ${ }^{108}$ On the other hand, the fear of infection was deep-seated; forced isolation, so it was believed, would prevent the spread of dysentery through the hospital. ${ }^{109}$ As with leprosy, the available drugs and the wider disease context shaped one another and the doctors' response to the illness. Trialand-error testing of new drugs was the obvious reaction to a desire to avoid isolating patients or exposing them to unpleasant side effects. Unlike other doctors in the colonies, including some of his own, Schweitzer was more concerned about what he regarded as emetine's doubtful efficacy than its negative side effects, as will be discussed below.

Another strategy to stop the spread of the disease saw repeated measures being taken to improve the hospital's water supply in order to minimize

102 Nessmann, Avec Albert Schweitzer de 1924 à 1926, 192. Keller was a missionary at the neighboring Protestant station.

103 Schnabel, 'Von ärztlichen Verrichtungen', 57.

104 Ibid., 60.

105 Schweitzer, 'Briefe aus dem Lambarene Spital Pfingsten 1931', 2.

106 Schweitzer, 'Briefe aus dem Lambarene Spital März 1938', 5 .

107 Schweitzer, Das Spital im Urwald:Aufnahmen von Anna Wildikann, 14, 20.

108 This was even more important for patients being treated for intestinal worms. See: Schweitzer, 'Neues von Albert Schweitzer Februar 1925', 5; Schweitzer, 'Briefe aus dem Lambarene Spital Februar 1939', 3-4.

109 Schweitzer, 'Mitteilungen aus Lambarene. Zweites Heft, 1924-1925', 140-41; LauterburgBonjour, Lambarene: Erlebnisse einer Bernerin im afrikanischen Urwald, 16; Schweitzer, 'Briefe aus dem Lambarene Spital März 1938', 5 . 
contact with the amoeba-contaminated river water. For two days in 1927, for example, Schweitzer searched the local area for a longer pipe to serve the hospital's ever-deepening well, acquiring one 'by flattering and begging."110 The institution's pump was regularly out of order, during which time patients had no choice but to drink the contaminated river water from nearer to its bank. For this reason, a rainwater reservoir and a deeper well with its own pump were built during the dry season in $1931 .{ }^{111}$ By the end of the decade, water supply had become insufficient once again. This forced patients to drink river water once more, in response to which another well was dug. ${ }^{12}$ The pumps had to be replaced on a regular basis (see Illustrations $3^{1}$ and $3^{2}$ ). Fear of dysentery among patients in case of neglect was a main argument therefor. 'Because when the patients drink river water we constantly have dysentery', Schweitzer explained to Emmy Martin in June 1950. ${ }^{113}$ Nurses who worked at the hospital in the 1960 s recalled a still precarious water supply and claim that all water was boiled before consumption. ${ }^{114}$

The significant attention paid to dysentery at the Albert Schweitzer Hospital, and the isolation of African patients in particular, carried with it a racial dimension. Dysentery posed a threat to Europeans at the hospital and in its wider vicinity. Various hospital employees contracted the disease, ${ }^{115}$ and it was among the three top reasons why Europeans were admitted to the institution, alongside malaria and gonorrhea. ${ }^{116}$ Europeans were also accused by the staff of underestimating the disease and of being ignorant of its dangers and transmission paths. Mathilde Kottman deputized as hospital director during Schweitzer's absence in 1928, the year after a severe dysentery epidemic. She wrote to Emily Rieder bemoaning this lack of knowledge. 'Fortunately, this year dysentery is not so widespread among the natives', she wrote. It was, however, more prevalent among Europeans, 'who often face this disease in a harmless and optimistic manner. They often hardly know that dysentery is contagious and transmissible!'117

110 Schweitzer to Martin, 11 March 1927, AMs.

111 Schweitzer, 'Briefe aus dem Lambarene Spital Pfingsten 1931', 2; Schweitzer, 'Briefe aus dem Lambarene Spital Februar 1934', 6.

112 Schweitzer, 'Briefe aus dem Lambarene Spital März 1938', 6.

113 Schweitzer to Martin, 27 June 1950, AMs.

114 Interview Elisabeth Anderegg; Stark-Bernhard, 'Waschfrauen, Büglerinnen, Schneider und Matratzenmacher', 28.

115 Dr. Victor Nessmann was infected with dysentery several times in 1926. See: Schweitzer to Martin, 12 March 1926, AMs. Another case was the nurse Erna Frischknecht in 1938. She was sent home soon. See: Schweitzer to Martin, 6 September 1938, AMS.

116 These numbers are taken from the 'Statistiques de l'Hôpital', L - A - S1-3, AMs.

117 Kottmann to Rieder, 27 November 1928, AwHS. 


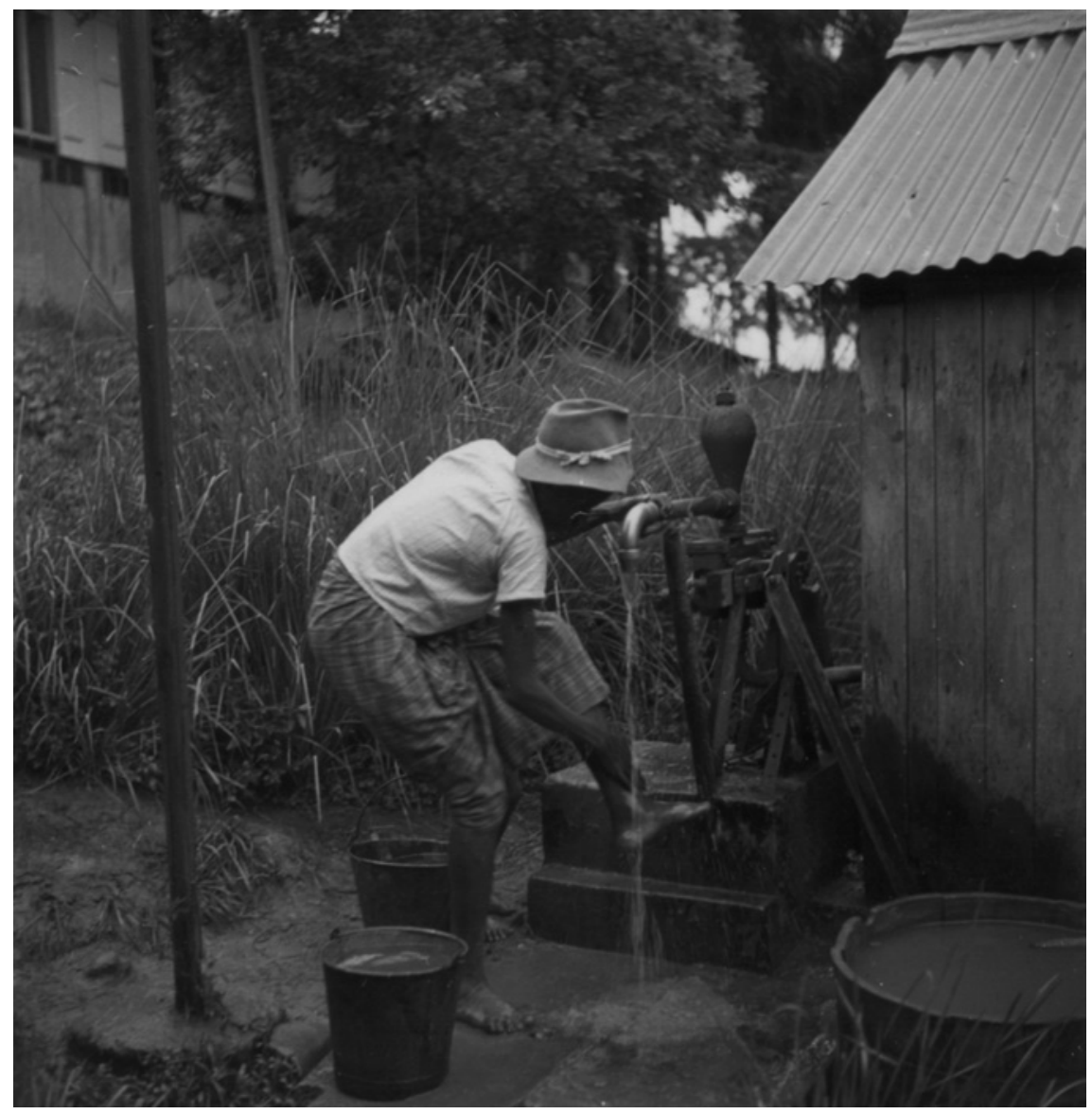

ILluStration 31 A pump at the hospital, undated

(C) ARCHIVES CENTRALES ALBERT SCHWEITZER GUNSBACH

At first glance, Figures 11 and 12 suggests that dysentery epidemics among Europeans did not necessarily coincide with outbreaks among Africans. ${ }^{118}$ Europeans were affected by serious epidemics in 1933 and, to a lesser extent, 1934. In contrast, dysentery cases among Africans were not significantly higher in those years than in others, neither in absolute terms nor relative to total patient admissions. However, 1933 is one of the few years for which detailed statistics from the government clinic in Lambaréné are available. These show that it recorded 136 dysentery cases, 108 of which were among outpatients. In the previous year, a total of 63 cases among Africans were recorded, 71 percent of whom

118 The numbers for both figures are taken from the 'Statistiques de l'Hôpital', L - A - S1-3 AMS. 


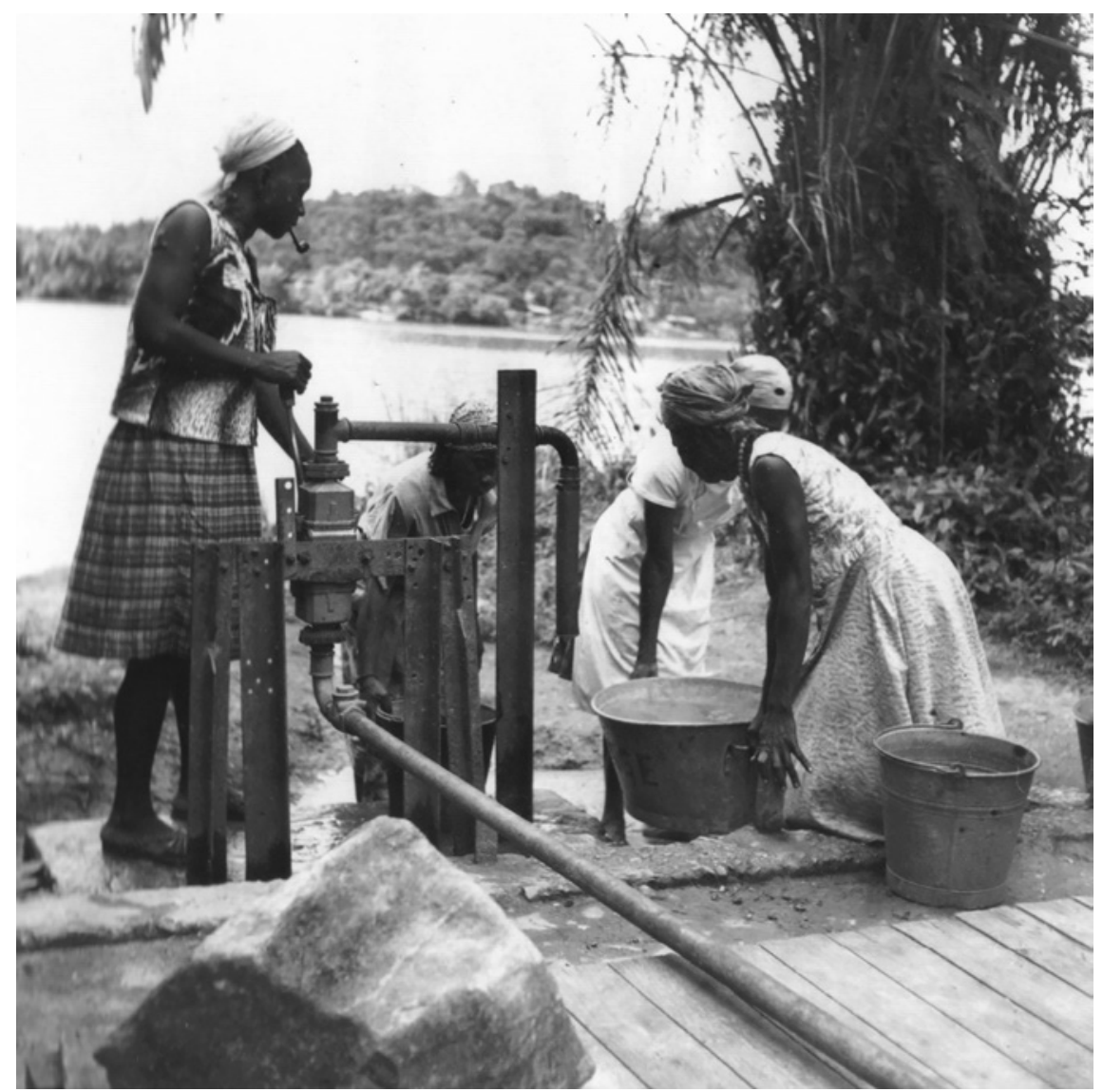

ILLUSTRATION 32 Another pump at the hospital, also undated

(C) ARChives CENTRALES ALBERT SCHWEITZER GUNSBACH

were treated on an ambulant basis. ${ }^{119}$ This small sample of evidence suggests that Africans were affected by the same dysentery epidemics as Europeans. This seems even more plausible when considering the fact that statistics from the Albert Schweitzer Hospital reveal that the total number of outpatients in both years was more than three times lower than the corresponding figures for the government facility, which Gabonese appear to have favored for ambulant treatment. $^{120}$

119 See the Rapports Annuels du Service de Santé de la Colonie du Gabon for 1932 and 1933, ZK 005-127, SHD. The hospital did not provide statistics for 1934, while the Service de Santé's annual reports for 1935 to 1945 are missing in Toulon.

120 In 1933, for example, Schweitzer's hospital reported 1,829 ambulant cases, whereas the government clinic recorded at least 6,250 , a figure that, considering unclear recordkeeping, might have been as high as 8,866. In 1932, the government facility recorded 5,545 


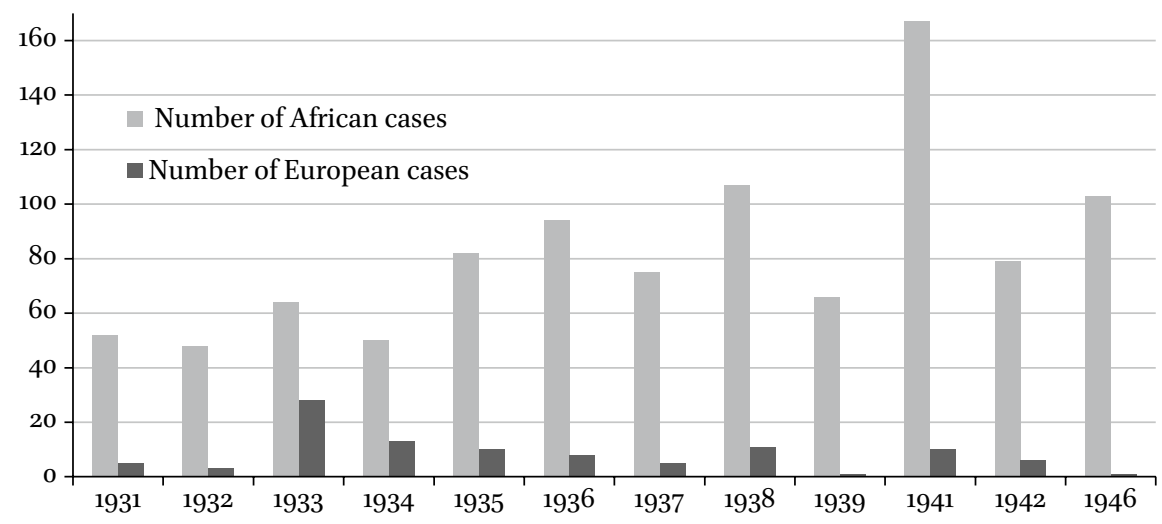

FIGURE 11 Patients diagnosed with dysentery

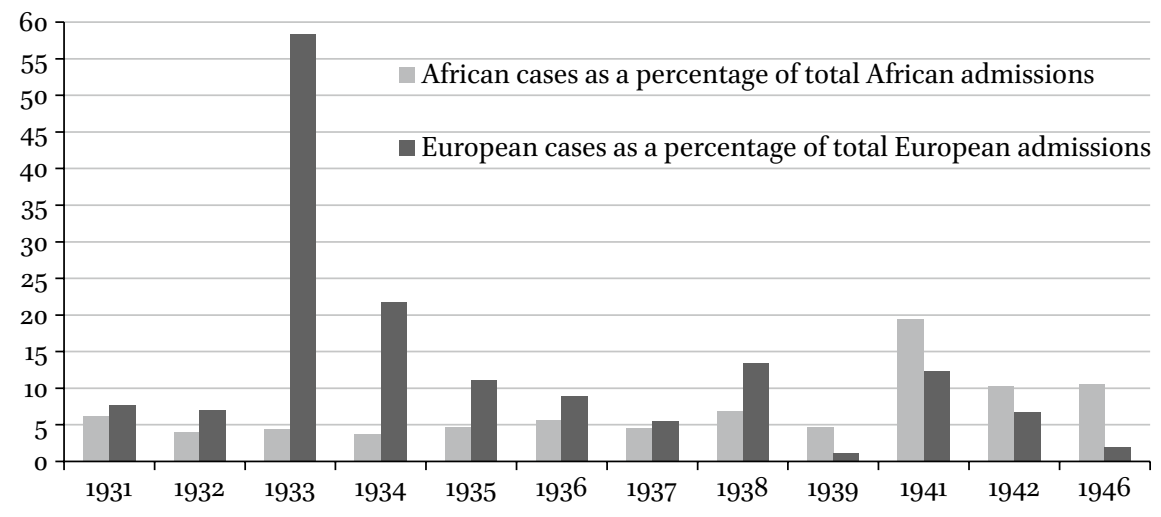

FIGURE 12 Dysentery cases related to total entries

The number of African dysentery patients at the hospital was particularly high during World War Two (see Figure 11), especially when considered in relation to total admissions during this period (see Figure 12). This implies that the disease was considered to be a serious concern, both by the patients, who actively sought treatment, and by the hospital staff, who admitted them while rejecting persons with other afflictions. It might further suggest local food scarcities, increased population densities in the area, burgeoning local lumber exploitation, and/or a closure of the government hospital. A more detailed analysis of these issues is beyond the scope of this chapter.

outpatients, as opposed to 1,445 at the Albert Schweitzer Hospital. For the source of these statistics, see the previous two footnotes. 


\section{Trials and Errors: the Use of Pharmaceuticals at the Albert Schweitzer Hospital}

In the treatment of dysentery and leprosy patients with pharmaceuticals a pattern can be discerned. Towards public and private sponsors, Schweitzer would praise a globally known standard drug, which was routinely administered to patients (see Illustrations 33, 34, and 35). ${ }^{121}$ In daily practice, however, doctors' in Lambaréné had to confront the fact that every drug came with its own flaws, which could relate to the form in which it was administered, its efficacy, and/or its side effects. In an attempt to mitigate these faults, the doctors tested alternative or additional options via a trial-and-error approach. In this subchapter, I analyze efforts to find more patient-friendly dosage forms, improve efficacy, or reduce side effects respectively by way of three examples: chaulmoogra, emetine, and sulfones. These drugs, or their trialed alternatives, were most frequently discussed in the sources in relation to the issues raised

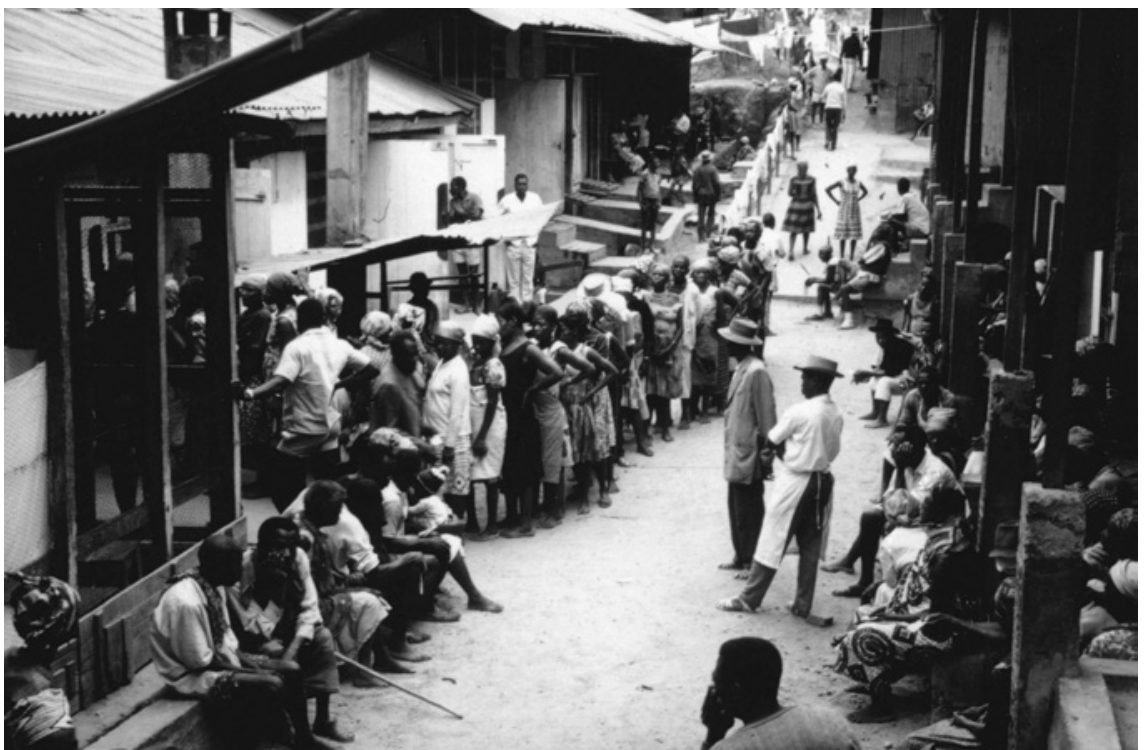

ILLUSTRATION 33 Patients queuing in front of the 'Grande Pharmacie', possibly for drugs, mid-1950s

(C) ARCHIVES CENTRALES ALBERT SCHWEITZER GUNSBACH

121 See Chapter 1 for a description of how the distribution and administration of drugs occurred at the hospital. 


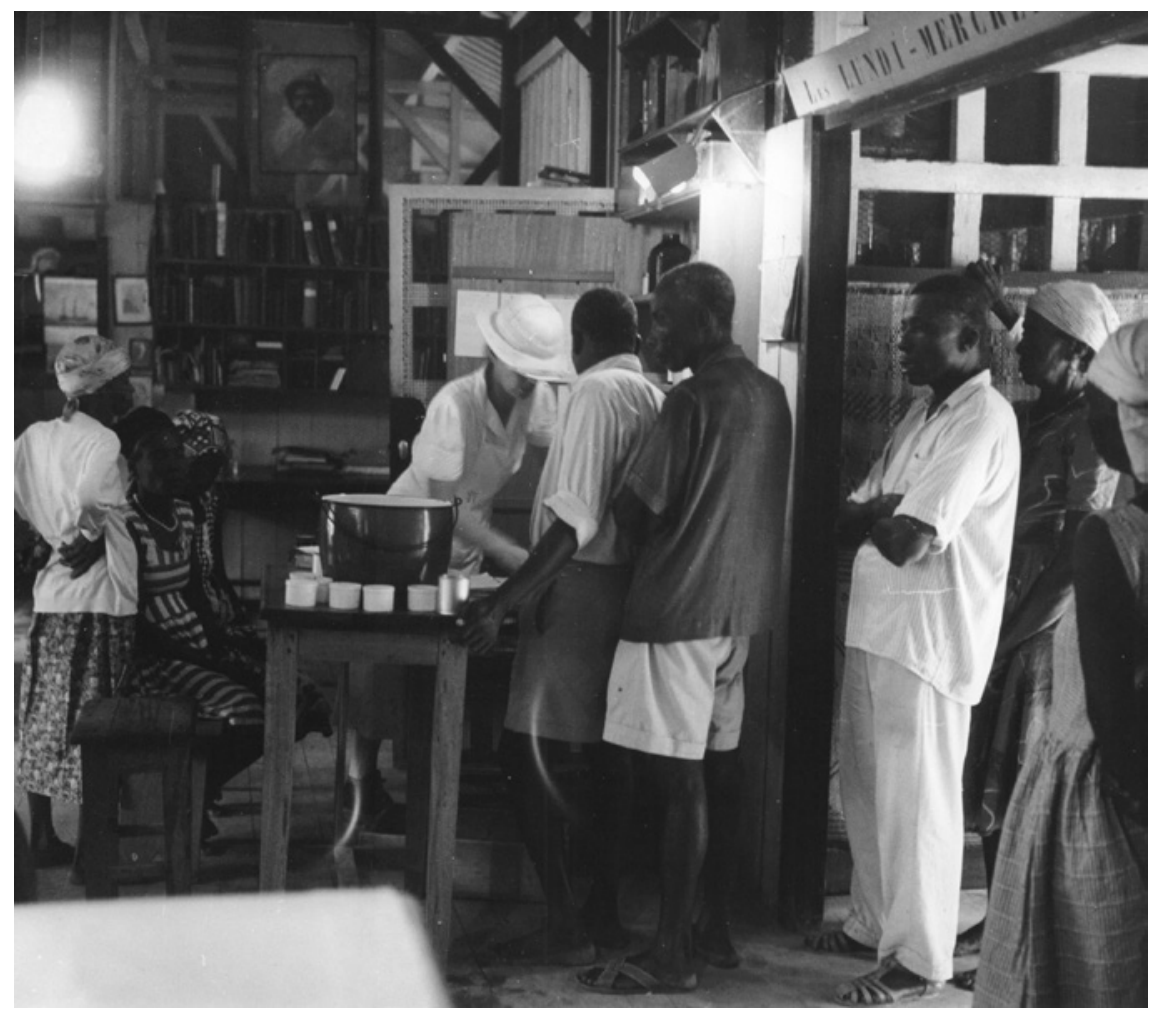

illustration 34 Inside the 'Grande Pharmacie' during the distribution of medication, mid-1950s

(C) ARChives CENTRALES ALBERT SCHWEITZER GUNSBACH

in the respective examples, which is not to imply that these concerns were not expressed in relation to other drugs.

I argue that the treatment of leprosy and dysentery was rather representative of drug use at the Albert Schweitzer Hospital, and presumably beyond it. Certainly, some common infectious diseases, such as yaws and syphilis, could be treated with relatively efficacious drugs. Others, such as malaria or tuberculosis, would need a more detailed analysis to make more informed claims. The frequent parasitic diseases habitually demanded a combination of various pharmaceuticals; a trial-and-error approach for determining the most appropriate arrangement would be no surprise. My observations from the surgical and obstetrical wards have shown that staff administered drugs in a liberal manner. The same is true for the psychiatric unit, where the process of deciding which medication to administer to a patient followed a pattern that was similar to the one being described now. Ulcers could likewise be targeted with 


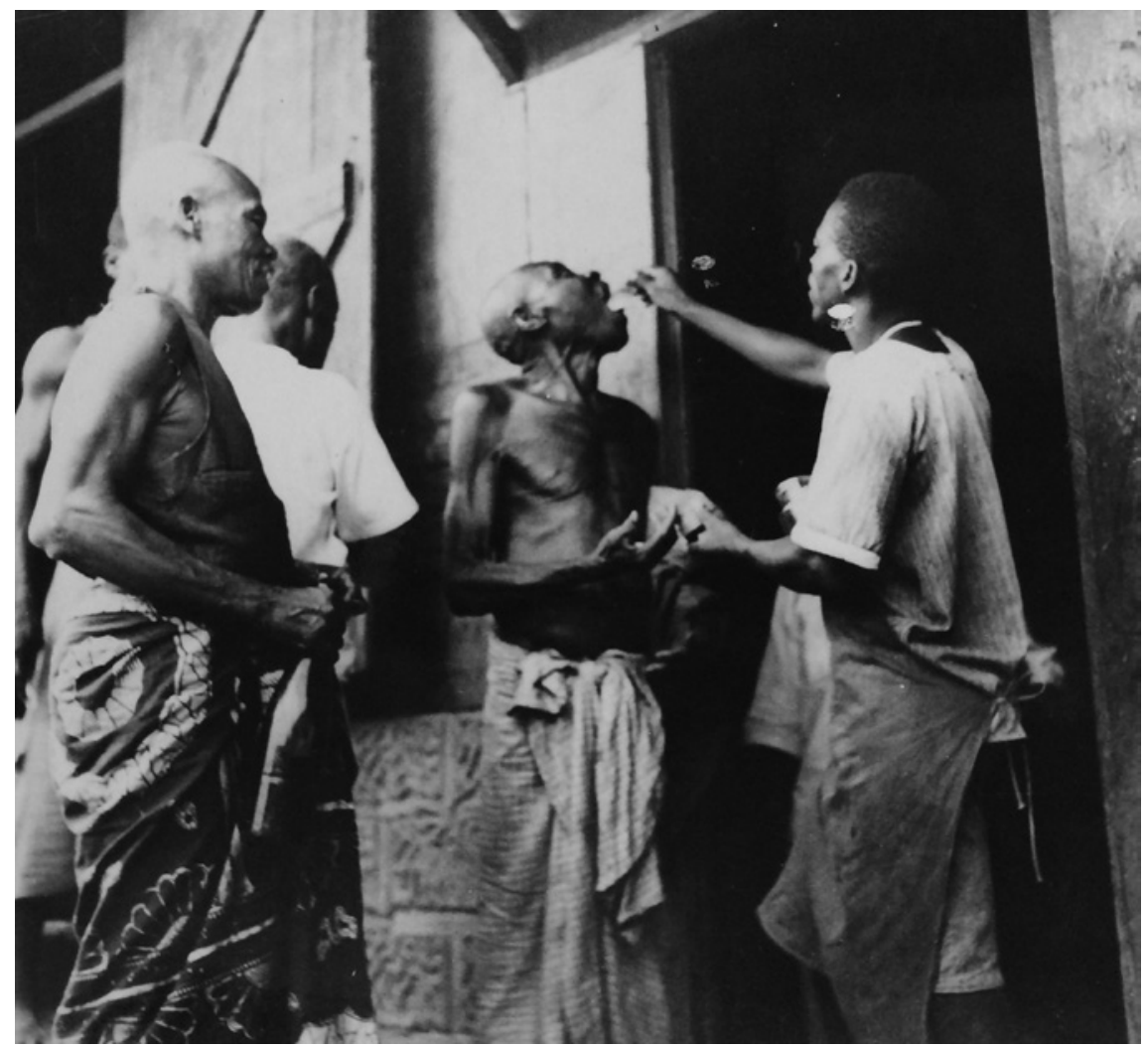

ILLUSTRATION 35 Patients receiving their medication under the supervision of medical personnel, mid-1930s

(C) ARCHIVES CENTRALES ALBERT SCHWEITZER GUNSBACH

a range of pharmaceutical options. Staff's methods to find the most effective approach and substance clearly resembled those observed in this chapter. ${ }^{122}$

Schweitzer, like many other colonial doctors in the 1920s and 1930s, had a reputation for conducting trials. Some pharmaceutical companies shipped their new drugs directly to Lambaréné without prior arrangement, expecting reports on the results obtained in tests on patients. ${ }^{123}$ Others, such as the French company Poulenc Frères, delivered Schweitzer's orders with the request that

122 Mabika Ognandzi, Steinke, and Zumthurm, Schweitzer's Lambaréné: A Hospital in Colonial Africa.

123 The Chemisch-Pharmazeutische Aktiengesellschaft Bad Homburg sent four cases of various medications, as its director informed Schweitzer in an accompanying letter. See: Abelmann to Schweitzer, 28 August 1929, AMs. 
he would communicate 'the results of (the) experimentation', as was the case for a consignment of emetine in 1929. ${ }^{124}$ One year later, Schweitzer agreed to test Simaran, another dysentery drug, for the German firm Degen and Kuhn. ${ }^{125}$ In 1931, the German corporation Bayer contacted Schweitzer, locating him in 'La Mbarene, Belgisch Congo'. The company sent a 'trial amount' of its new arsenic 4005, for which encouraging reports had emerged from dysentery treatment trials in Spanish Guinea. The Bayer representative, aware that various drugs were trialed at Schweitzer's hospital, added that his employer would be 'be very grateful if you could also include this preparation in the frame of your experiments. ${ }^{126}$ None of these companies specified what kind of comments or results it required or expected; instead, they were simply interested in the information that could be derived from Schweitzer's 'experiences' in testing a drug's effects on actual patients.

\subsection{Chaulmoogra and Dosage Form}

Disregarding the pain of the injections and their doubtful impact on the disease, Schweitzer described the treatment of leprosy with chaulmoogra oil in his first newsletter from Lambaréné as being very successful. 'You don't really achieve real cure. But at best you get results that are so perceptible and durable that it almost equals cure', he wrote. ${ }^{127}$ After his return to Europe, he reviewed these circulars and published them in his popular memoir On the Edge of the Primeval Forest in 1921. In his revisions, Schweitzer was even more optimistic about the therapeutic potential of chaulmoogra, claiming that 'in any case, one can observe improvement and long lasting arrestment of the disease, which sometimes almost equals cure.'128

It has been well documented how Schweitzer aspired to contribute to the advancement of chaulmoogra oil therapy in the $1920{ }^{129}$ His efforts focused on making its associated injections less painful in order to increase patients' willingness to undergo the treatment. He aimed to find a diluter that would allow injections to be administered using the less painful subcutaneous method. He was thus willing to pay Professor Gustav Giemsa of the Bernhard Nocht Institute of Tropical Medicine in Hamburg for advice. Giemsa had conducted a series of tests on dogs, ultimately recommending peanut oil as a diluter. In his trials, this had allowed chaulmoogra oil to be injected subcutaneously,

\footnotetext{
124 This letter is catalogued as: De Pulligny to Schweitzer, 30 April 1929, AMs. Italics mine.

125 Degen \& Kuhn to Schweitzer, 28 August 1930, AMS.

126 Bayer to Schweitzer, 7 August 1931, AMs.

127 Schweitzer, 'Notes et Nouvelles de la part du prof. Albert Schweitzer Lambaréné', 11.

128 Schweitzer, Zwischen Wasser und Urwald, 87.

129 Ohls, Der Arzt Albert Schweitzer, 199-205.
} 
presumably without complications, ${ }^{130}$ which would nevertheless develop when the method was later applied to patients in Lambaréné.

Aware of the limited efficacy of chaulmoogra, Schweitzer conducted trials with an arsenic compound in 1931 at Giemsa's request. Although the latter had tested this successfully on dogs, Schweitzer reported negative results after he had administered it to some of his patients, as did other doctors in various parts of Africa. He did, however, report some promising test results for fighting leprosy with Trypaflavin, a well-known medication already used to treat sleeping sickness. Giemsa was enthused by these and encouraged Schweitzer to continue the trials:

I would be extremely interested to hear from you about your further experiences with trypaflavin, on whose results it will depend, whether it seems necessary to further expand the chemotherapy of leprosy with acridine derivatives. What an unexpectedly beautiful surprise it would be if it would finally be possible to free humanity from this probably worst of all scourges!131

In a typically optimistic and exaggerated tone, Giemsa assigned a key role to Schweitzer in the fight against leprosy. However, no correspondence between the two doctors from after January 1933 is held in Gunsbach, suggesting that their cooperation ended abruptly..$^{132}$

During their Trypaflavin trials, doctors at the Albert Schweitzer Hospital still preferred to treat leprosy with Bayer's chaulmoogra compound, Antileprol. ${ }^{133}$ This was a widely-used drug that was administered using the painful intramuscular method. ${ }^{134}$ In April 1934, however, Dr. Goldschmid began injecting it intravenously and was pleased with the outcome, which promised better results and less frequent side effects. He also emphasized that patients preferred this method and were willing to submit to it more readily, aspects not typically

130 Giemsa to Schweitzer, 6 September 1924, AMs.

131 Giemsa to Schweitzer, 14 January 1932, AMs. The digitized file is wrongly dated 13 November 1932 .

132 Isgard Ohls, who has consulted the archives of the Bernhard Nocht Institute in Hamburg, also does not refer to any documents relating to Giemsa from after 1933, but she does not reflect on this sudden rupture in his relationship with Schweitzer. See: Ohls, Der Arzt Albert Schweitzer, 223-24. Support for Hitler shown by Giemsa, the institute's founder, Nocht, and its director, Peter Mühlens, might be one explanation for this cessation of correspondence. See their entries in: Klee, Das Personenlexikon Zum Dritten Reich.

133 Schweitzer, 'Briefe aus dem Lambarene Spital Pfingsten 1931', 7.

134 Klingmüller and Grön, Die Lepra, 697. 
considered by doctors at Lambaréné. Respecting Schweitzer's desire to cast a controlling eye over his hospital, Goldschmid sent the following favorable synopsis of his trials:

\begin{abstract}
Also, the results of intravenous injections are much better than those of intramuscular ones. With intramuscular injections I also observed too many abscesses (almost every week I had to cut open an abscess). Since we have been injecting intravenously, patients have been much more willing to undergo Antileprol injections. I am waiting for further instructions from you in this regard. I can say that I can take responsibility for the efficacy of the intravenous method. ${ }^{135}$
\end{abstract}

However, doctors at the Albert Schweitzer Hospital were not fully satisfied with the intravenous Antileprol method and continued to look for alternatives throughout the 1930s. In October 1934, Goldschmid tested methylene blue injections in the hope that they would complement the Antileprol treatment and render it more efficacious, reporting to Schweitzer that the 'results justify the continuation of the tests.' ${ }^{136}$ Methylene blue was used extensively in the hospital throughout the study period as a disinfectant for ulcers and other skin lesions, ${ }^{137}$ but it would never become a viable alternative for the treatment of leprosy as such.

During World War Two, diphtheria toxin was used to treat leprosy. Once more, Schweitzer was optimistic about its efficacy, writing to Edward Hume that 'with this drug you really see successes.' ${ }^{138}$ In his first circular after the war, Schweitzer revealed that the compound would be combined with chaulmoogra, arsenics, Trypaflavin, and methylene blue in an injection. The efficacy of this cocktail is doubtful, the shots were painful and their side effects severe. In Schweitzer's view, however, the main obstacle to a cure for leprosy was African patients' inability to comply with doctor's orders. 'Today, as in the past, the poor sick lack the necessary patience', he reasoned. He further declared that there was new hope for fighting the disease more effectively in the future due to promising trials conducted by French doctors in Madagascar with a drug

\footnotetext{
135 Goldschmid to Schweitzer, 12 June 1934, AMs.

136 Goldschmid to Schweitzer, 31 October 1934, AMs.

137 Schweitzer, 'Mitteilungen aus Lambarene. Erstes Heft, 1924', 44; Goldwyn, 'Diary 1960', AMs, 56 . Elsewhere in the tropics, it was also used to treat malaria. See: Prins, 'But What Was the Disease?', 160.

138 Schweitzer to Hume, 6 April 1943, Ams.
} 
derived from the plant Hydrocotylus asiatica, while American trials with Promin had yielded similarly encouraging results. ${ }^{139}$

\subsection{Emetine and Efficacy}

The treatment of dysentery at the Albert Schweitzer Hospital followed a plot that resembled the one of leprosy until the end of the 1940s. The standard drug, equivalent to chaulmoogra for leprosy, was emetine. Schweitzer had praised emetine's efficacy since his first stay in Lambaréné. In On the Edge of the Primeval Forest, he wrote about its miraculous effects: 'If you inject it for several days in a row into the skin, improvement, and usually lasting cure, can soon be observed. Successes resemble a miracle. ${ }^{140}$ In 1931, Dr. Bonnema reported more soberly that 'emetine provides good benefits, usually people don't need more than $40 \mathrm{mg}$ per day'.141 In addition, Yatren, a sulfonic acid combined with iodine and manufactured by Behring, was administered on a regular basis, especially for chronic cases. ${ }^{142}$ In 1936 , Goldschmid assessed the treatment of dysentery, concluding that 'the combined emetin and yatrène treatment still proves to be the best therapy'. ${ }^{143}$ Side effects, for which emetine was frequently known and which often led to forced isolation of patients, were not mentioned. This positive, straightforward evaluation notwithstanding, the sources reveal that a variety of trial-and-error tests on patients were undertaken with further drugs.

Patient records provide only a limited insight into dysentery treatment patterns. However, there is an eleven-month period from July 1928 to May 1929 when the records of European and African patients overlap, as illustrated in Figure $13 .{ }^{144}$ During this time, dysentery cases were relatively frequent among both groups. Emetine constituted the major treatment for both groups, with 88 percent of African patients and 81 percent of European patients receiving it. Approximately one-third of patients in each group were treated exclusively with emetine. When additional drugs were administered, these often included medications to treat other afflictions, such as heart conditions, intestinal parasites, or to improve their general state of health. The limited data overlap suggests that Yatren was more frequently prescribed to Europeans (in 35 percent

139 Schweitzer, 'Briefe aus dem Lambarene Spital März 1946', 12-13. Possibly, Schweitzer meant Hydrocotyle asiatica.

140 Schweitzer, Zwischen Wasser und Urwald, 88.

141 Bonnema to Schweitzer, 2 March 1932, AMs.

142 Schweitzer, 'Mitteilungen aus Lambarene. Zweites Heft, 1924-1925', 140-41.

143 Goldschmid to Schweitzer, 16 July 1936, AMs.

144 European patient records commence in this period, just as African patient records come to an end. See: $\mathrm{L}-\mathrm{P}-\mathrm{C} 1-16, \mathrm{~L}-\mathrm{P}-\mathrm{E} 1$, AMs. 


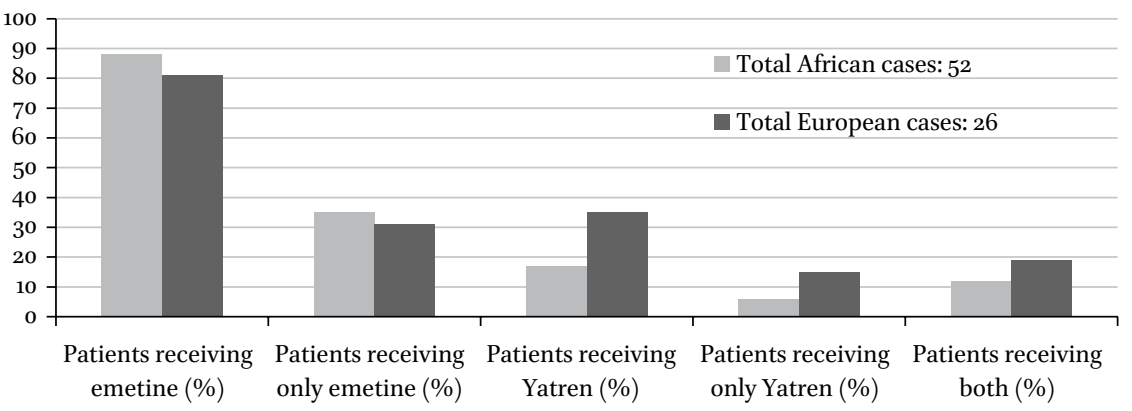

FIGURE 13 Dysentery treatment, July 1928 to May 1929

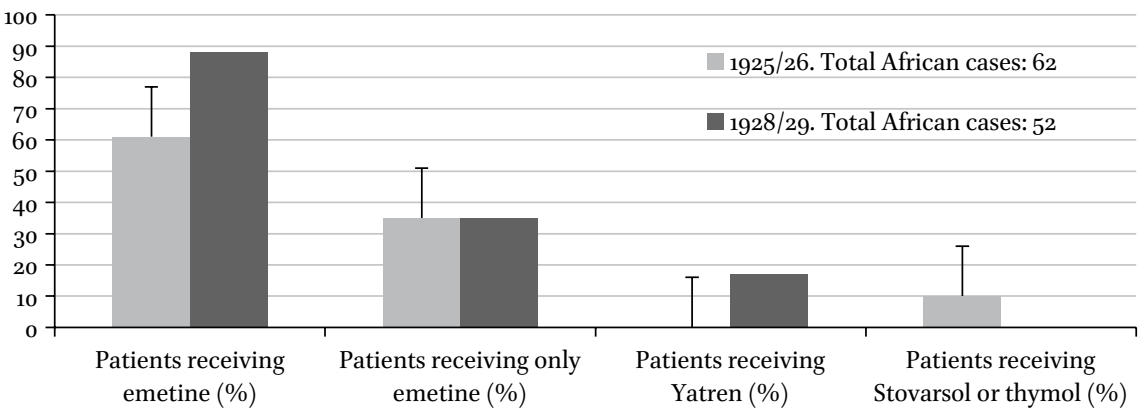

FIGURE 14 Developments of dysentery treatment

of cases) than to Africans (in 17 percent of cases). This tendency was based on medical observations: European cases were more often diagnosed as chronic, and cysts were more regularly detected among Europeans, both indications for the use of Yatren. However, the time period for the comparison is too narrow and the number of cases too low to draw broader conclusions from these observations.

A slight change can be observed when comparing the treatment of Africans in 1928/29 to that at the corresponding time of three years earlier, as Figure 14 illustrates. ${ }^{145}$ As Schweitzer described in a newsletter, the summer of 1925 was marked by a dysentery outbreak. 'The contamination of the hospital with dysentery is progressing', he wrote, specifying that 'almost every day a new patient

145 The records from $1925 / 26$ list a further ten dysentery patients without specifying the treatment that they underwent. As a result, it is not known whether they received any medication, and, if they did, whether this was emetine, the most likely prescription. In Figure 14, this uncertainty is represented by the vertical black lines in each category. 
who has contracted the disease is discovered. And dysentery patients continue to be brought in'. ${ }^{146}$

Yatren is mentioned for the first time in the same publication, with Schweitzer claiming that it worked better for chronic cases than emetine. ${ }^{147}$ The latter was already the most commonly used drug for treating Africans at the time, albeit to a lesser degree than in 1928. The percentage of African patients who only received emetine was identical in both periods. Despite Schweitzer's praise for Yatren, it was not administered to Africans in 1925 . Instead, Africans were treated with thymol and Stovarsol, among other drugs, but both of these medications do not appear in the records three years later. This limited set of data suggests that some drugs, such as Yatren, were prioritized for Europeans, a practice justified with reference to medical imperatives. Given that Africans did receive Yatren in 1928, it could indicate that promising drugs were first tested on Europeans, but there are no remarks in the sources to support such a reading.

As with chaulmoogra in relation to leprosy, emetine's leading role in the fight against dysentery was frequently challenged. While dosage form represented a primary concern in the case of chaulmoogra, the main doubt arising from trials with emetine was the drug's efficacy, and not, as might have been expected, its side effects. A variety of compounds were trialed as alternatives, as the quotation at the beginning of this chapter suggests. Schweitzer's comment cited there was his response to the following paragraph written by Dr. Barasch in November 1936 and illustrates the doctors' hope to find a more efficacious drug against dysentery:

According to your wish I treat some cases of dysentery with iodalginemetine instead of yatrine-emetine. Maybe - but I don't believe it - it will be possible to do without the yatrine in the future; you certainly won't be able to do without the emetine because so far it is the only reliable remedy against the amoebae themselves. Iodine preparations only have an effect on the kysts. ${ }^{148}$

Throughout 1936, Schweitzer had regularly inquired about the effects of Jodalgin, a compound distributed by his friend Paul Gloess, who had a pharmaceutical laboratory in Paris, as a substitute not only for Yatren, but also emetine. In

146 Schweitzer, 'Mitteilungen aus Lambarene. Zweites Heft, 1924-1925', 156-57.

147 Ibid., 140.

148 Barasch to Schweitzer, 24 November 1936, AMs. 
August, there were not enough dysentery cases at the hospital to allow meaningful conclusions about Jodalgin's efficacy to be drawn. ${ }^{149}$ Two weeks before Barasch's above-cited letter, Goldschmid also expressed his doubts about the drug, explaining to Schweitzer that it is very difficult to indicate the value of Gloess' iodine preparations for dysentery, as it would be too risky to use them without emetine. ${ }^{150}$ Goldschmid thereby invoked his clinical experience to reject Schweitzer's request to have the new drug tested, arguing that the existing treatment was sufficiently efficacious. As we will see below, Schweitzer employed similar reasoning himself on a number of occasions.

In the case of Jodalgin, it was Schweitzer who requested the testing of the new drug, rather than any doctors at the hospital out of their daily practices and observations. The trials were not successful, if indeed any were ever held. Less than a year after the above exchanges with his doctors, Schweitzer wrote in his notebook that the 'Gloess preparation is not so effective against dysentery itself, but it increases the effect of emetin and reduces its side effects'.151 While Schweitzer did refer to side effects here, he claimed that Jodalgin had been rejected because its efficacy was lower than that of emetine. Jodalgin does not appear again in the sources; other drugs once considered failed could regain favor at a later stage.

The arsenic Stovarsol, which was manufactured by Poulenc and was a wellknown treatment for syphilis, was used at the Albert Schweitzer Hospital to combat dysentery in the mid-1920s. ${ }^{152}$ In the first week of May 1925, Schweitzer was called to a lumber camp where 31 out of 107 workers had contracted dysentery in mid-April, 16 of whom passed away within the following two weeks. Schweitzer reported to the district administrator that the sanitary conditions were nevertheless 'perfectly satisfying' and treated all affected persons with three shots of emetine. Patients who continued to excrete blood were taken to the hospital, while the rest were left in isolation at the camp, where they received Stovarsol. ${ }^{153}$ At the hospital, Stovarsol was prescribed alongside emetine, but was also considered sufficiently efficacious to be administered on its own, as Figure 14 indicates. After 1928, the drug was no longer prescribed for dysentery. In contrast, Dr. Ilse Schnabel, who served at the hospital from 1928 to 1930, expressed her doubts about its efficacy in a medical journal article,

\footnotetext{
149 Goldschmid to Schweitzer, 16 August 1936, Ams.

150 Goldschmid to Schweitzer, 10 November 1936, AMs.

151 See of the notebook '1930 Therapeutische Notizen', 111, AMs. Schweitzer used the book until 1940. It is not possible to discern the exact date of each passage, since Schweitzer only occasionally entered dates in these notebooks.

152 Trensz, 'Le médecin', 214.

153 Schweitzer to Garnier, 5 May 1925, AMs.
} 
claiming that Stovarsol would not deliver 'encouraging successes'. ${ }^{154}$ The drug does make another appearance on Schweitzer's personal list of seven different dysentery treatments in 1934 (see Illustration 36 ). ${ }^{155}$ In the 1940 , it was routinely applied in combination with emetine and coffee charcoal to treat chronic cases. ${ }^{156}$

A similar case was that of Enterovioform, an antifungal and antiprotozoal drug produced by the Swiss company Ciba. Schweitzer wrote in his notebook that he had recorded positive results with the drug in February 1939 and had thus requested 'larger trial quantities to test the drug on the (good old) emetine.'157 Enterovioform was frequently prescribed at the hospital by the end of the 1950s, but details on how exactly and rapidly doctors at Schweitzer's reached a positive conclusion about its usefulness cannot be discerned from the sources. ${ }^{158}$ Common to the Enterovioform, Stovarsol, Jodalgin, and Yatren trials was that they were not conducted with the primary aim of finding a dysentery treatment with fewer side effects. ${ }^{159}$ Instead, these drugs were trialed because it was hoped that they might prove to have greater efficacy than emetine or be able to maximize its effects.

In a letter to Eugen Bernoulli, a leading Swiss pharmacist, Schweitzer maintained that emetine, when injected subcutaneously, was both non-toxic to humans and highly efficacious against the amoebae that cause dysentery, but on the condition that one always uses 'freshly prepared solutions, not older than 24 hours and stored away from light, no ampullae'. Schweitzer justified his challenge of Bernoulli's pharmaceutical authority with reference to his own abundant experience. 'I who so often work with emetine, practically don't know of any malfunctions or toxic side-effects', he wrote. ${ }^{160}$ Schweitzer emphasized

154 Schnabel provides a long list of compounds that were given to dysenteric patients, often alongside emetine: calomel, bismuth subnitrate, kaolinite, Elkosam, simaruba, as well as tea and rice gruel, and Yatren for chronic cases with cysts. See: Schnabel, 'Medizinisches aus Albert Schweitzers Urwaldspital', 3 .

155 Schweitzer's six other treatment options were: two different mixtures containing Yatren, bismuth, and chalk; emetine; Novarsénobensol; Yatren; and Rivanol. See the notebook '1930 Therapeutische Notizen', 59, AMs.

${ }_{15} 6$ Schweitzer, Das Spital im Urwald: Aufnahmen von Anna Wildikann, 13.

157 See the notebook '1930 Therapeutische Notizen', 133, AMS.

${ }_{15} 8$ The hospital issued about 3,00o pills per month, approximately 1,00o of which were given to leprosy patients, to treat unspecified forms of diarrhea, or amoebic dysentery. See: Friedmann to Schweitzer, 6 November 1957, AMs.

159 Although no side effects were reported from the trials, it is unlikely that none occurred.

16o Schweitzer to Bernoulli, 20 April 1950, AMs. In this letter, Schweitzer thanked Bernoulli for having published the seventh edition of his pharmaceutical encyclopedia in 1949, which he considered to be the most practical handbook on the market. Bernoulli and his co-editor therein recommended emetine to be injected either intra-muscularly or intravenously. In the next edition of 1955 , they do not mention the subcutaneous option 


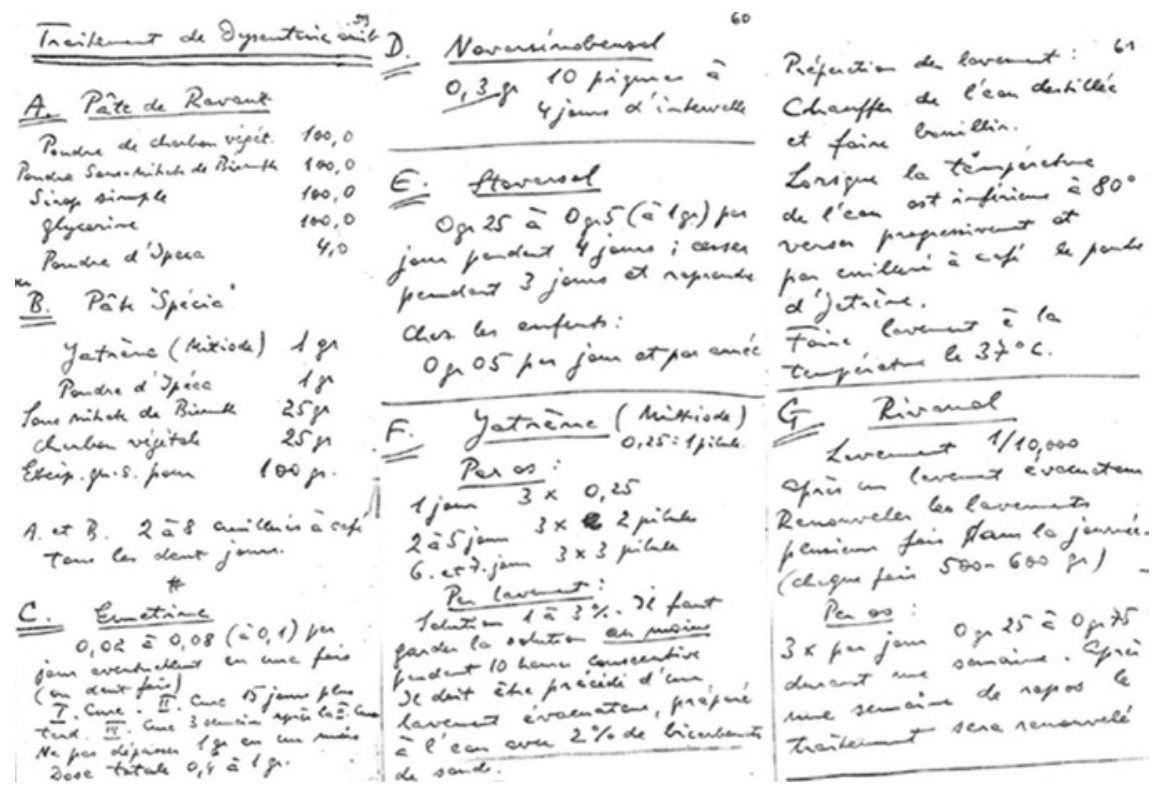

ILLUSTRATION 36 Schweitzer's notebook with the seven different treatments for dysentery, 1934

(C) ARCHIVES CENTRALES ALBERT SCHWEITZER GUNSBACH

his belief that, contrary to common perceptions, emetine had almost no side effects, but he also highlighted its high efficacy. Emetine trials were mostly concerned with efficacy, but it is likely that these trial-and-error tests also revealed a method to reduce its side effects. While not denying either of these benefits, specialists advised against injecting amoebic dysentery patients with emetine because this could render the disease-carrying amoebae resistant. ${ }^{161}$

Emetine was still in frequent use at the Albert Schweitzer Hospital after $1960 .{ }^{162}$ A 1969 report by the wHO indicates that this was not unusual at the time. The drug's side effects remained the major concern, to mitigate against which the report recommended emetine's use in combination with antibiotics. ${ }^{163}$ At

anymore. See: Lehmann and Bernoulli, Übersicht der gebräuchlichen und neueren Arzneimittel, 298.

161 In 1941, Philip Manson-Bahr, for example, recommended administering emetine bismuth iodide in capsules. See: Manson-Bahr, 'Amoebic Dysentery and Its Effective Treatment'. Philip Manson-Bahr was Patrick Manson's son-in-law and had adopted the family name after marriage. He edited the seventh to fifteenth editions of Manson's Tropical Diseases, a handbook first published by his father-in-law in 1898 . The twenty-third edition was published in 2014.

162 Cousins, Dr. Schweitzer of Lambaréné, 209; Müller, '50 Jahre Albert-Schweitzer-Spital', 11.

163 Powell, 'Drug Therapy of Amoebiasis'. 
Schweitzer's hospital, antibiotics were frequently prescribed in the post-surgery ward. Chloroquine was administered as a malaria prophylaxis, as was quinine for severe cases of the disease; penicillin injections were given to treat yaws; and gonorrhea and ulcers were treated with unspecified antibiotics. ${ }^{164}$ In 1963 , amoebic dysentery still represented a significant worry at the hospital, as Dr. Rolf Müller revealed in a medical journal article. In addition to emetine, he listed five further antiprotozoal drugs - but no antibiotics - as treatment options, of which Enterovioform is the only one discussed in this chapter. ${ }^{165}$ These preparations were considered to have a higher degree of efficacy than emetine and doctors had learned how to offset its side effects, both factors that go a long way towards explaining why references to dysentery largely disappear from the sources after 1950. It is conspicuous, however, that neither Schweitzer nor any of his doctors praised these new compounds in the manner that they had done for emetine or for sulfones in the case of leprosy.

\subsection{Sulfones and Side Effects}

While emetine remained an important option in the fight against dysentery throughout the study period, chaulmoogra fell considerably out of favor in the treatment of leprosy as a result of the development of sulfone drugs during World War Two. In 1946, Schweitzer expressed his optimism about these new drugs, writing that 'in America, a substance related to the sulfanilamides, Promin, is also being successfully tested. How glad we doctors who deal with leprosy patients will be once we have a faster and better treatment'. 166 Two years later, he told Albert Einstein that the new drugs being used at the hospital, Promin and Diasone, 'really achieve what those used until today could not'.167

In 1946, there were 34 leprosy patients at the hospital. ${ }^{168}$ This number rose to 150 in January 1951 and 350 in September of the same year, ${ }^{169}$ with some patients coming from as far as 400 kilometers away. Schweitzer believed that this

164 Müller, '50 Jahre Albert-Schweitzer-Spital', 12-13. In this article, Müller analyzes the diagnoses of 2,500 patients, including, unusually, those of outpatients. Infectious diseases represented 13.9 percent of these diagnoses, rendering them the second most common disease category after parasitic diseases (14 percent). Without providing further details, Müller briefly refers to 'anthelmintic therapy and iron therapy' as treatments for parasitic diseases (10).

165 The others were Entobex, Intestopan, Bemarsal, and Atebrin. Ibid., 11.

166 Schweitzer, 'Briefe aus dem Lambarene Spital März 1946', 13.

167 This letter is published in: Bähr, Albert Schweitzer: Leben, Werk und Denken, 187.

168 'Statistiques de l'Hôpital 1946', L - A - S3, AMs.

169 See the appels mensuels, $\mathrm{L}-\mathrm{P}-\mathrm{AM}_{7}$, AMs. 
influx of patients was due to the efficacy of the new sulfone drugs. ${ }^{170}$ With numerous variants of the drugs available, many trial-and-error tests were conducted at the hospital. These did not, however, provide conclusive evidence of the drug with the fewest side effects.

Despite this usual optimism, Schweitzer initially had his doubts about the efficacy of sulfones. In January 1950, he wrote to Robert Weiss, his long-time pharmacist in Strasbourg, explaining that he still preferred using chaulmoogra oil as the basic drug to dissolve the wax layer of the leprosy bacilli. These could then be targeted with copper or Trypaflavin, 'with which I have always seen successes in association with chaulmoogra oil. ${ }^{171}$ At this point, Schweitzer believed that the new sulfone drugs should be administered in combination with these proven compounds.

Schweitzer's initial perception of sulfones as merely complementary changed radically in a short period of time. Just four months after writing to Weiss, he sent Emmy Martin the following decidedly enthusiastic assessment:

I'm completely consumed by correspondence about new leprosy medications! A Parisian house 'Theraplix' has sent me a cheaper and at least as effective remedy to try, which is related to the American drugs but has the big advantage that it is taken through the mouth instead of intravenous injections. Yesterday I left everything, studied the question in the literature sent to me and placed my first order directly with the house, which I pay for from here. That leaves no time for anything else. But it is something wonderful, this simplification and price reduction of the whole fight against leprosy. All day long I staggered around like a donkey stunned by happiness (this time not by incense). The new remedy is called 'Disulone' with the scientific name 'Diamino-4-4Diphenylsulfone DDs. Sulfone 1350 F'. Please learn by heart... ${ }^{12}$

Ultimately, Disulone would not become the standard drug for the treatment of leprosy at the Albert Schweitzer Hospital. It is noteworthy, however, that Schweitzer underlined not only its lower cost and higher efficacy, but also its oral mode of application, which was favored by both patients and medical personnel. Diasone, which would become the most extensively used leprosy drug

170 He expressed this view in another letter to Einstein. See: Bähr, Albert Schweitzer: Leben, Werk und Denken, 209.

171 Schweitzer to Weiss, 9 January 1950, AMs.

172 Schweitzer to Martin, 16 May 1950, AMS. 
at the hospital, was also ingested orally, an advantage referred to elsewhere, ${ }^{173}$ but curiously rarely highlighted in the sources analyzed for this study.

Naegele, who arrived in February $195^{\circ}$ and served until May 1952, was the first doctor at the hospital to prescribe sulfone drugs on a regular basis. In 1950, he carried out a series of tests on which he reported in detail. ${ }^{174}$ Diasone was given on its own to 167 out of a total of 265 leprosy in- and outpatients. Naegele then matched the length of treatment and the amount of Diasone that each patient received with his or her condition, which he defined as 'improved, stagnant, aggravated, cured, deceased'. He concluded that 'the effect obtained is more or less directly proportional to the amount of sulfones ingested', but acknowledged that the number of patients was too low to draw any confident conclusions. Naegele was also interested in the question of side effects, summarizing that 'in general we had no difficulty with our four-week treatment (on average $15 \mathrm{~g}$ of Diasone) cut by a fifteen-day rest period', albeit with the qualification that an aggravation of typical leprosy symptoms often occurred immediately after the first application of the drug. ${ }^{175}$ Thirty of the remaining patients received Diasone as well as an additional drug - most frequently Trypaflavin. This trial also indicated encouraging results, but the hospital ran out of Trypaflavin during the course of the year. In a final trial, sixteen patients received either Disulone, which had excited Schweitzer so much, or its American prodrug equivalent, Promin, as a complementary treatment to Diasone. Naegele noted very promising results with Promin. It positively affected 'cases with general skin infiltration' and had 'a very noticeable influence on leprosy wounds.'.176

Half a year after these trials, Naegele provided updated results. He now claimed that Promin was the 'most superior sulfone'177 in terms of efficacy, but a closer examination of his explanation reveals that this observation was based on inconsistent evidence. ${ }^{178}$ Naegele observed that different patients reacted

173 Faget, Pogge, and Johansen, 'Present Status of Diasone in the Treatment of Leprosy', 961. See also: Gould, $A$ Disease Apart, 290.

174 Naegele, 'Traitement des malades lépreux à l'Hôpital du Docteur Albert Schweitzer à Lambaréné au cours de l'année 1950', AMs.

175 Ibid., 3 .

176 Ibid., 4 .

177 Naegele to Schweitzer, 4 June 1951, AMs.

178 A total of 21 patients received Promin, 106 received Diasone, and 32 received Disulone. In each trial, between 46 and 50 percent of the patients' conditions improved (10 with Promin, 49 with Diasone, 16 with Disulone). Between 38 and 46 percent of patients showed no change (8 with Promin, 49 with Diasone, 12 with Disulone). At 12 percent, Disulone provided the highest percentage of patients whose condition deteriorated. All three sulfones were administered for at least six months, "because this seems to be the "time limit" 
differently to different sulfones and concluded that 'probably those people are right who call for selecting the most effective and best tolerated sulfone for each patient anew.'179 This approach differed from that of many doctors in Africa and Europe alike, who aimed to find a standard drug or establish a standardized treatment regime for leprosy. At the end of 1951, Naegele shifted his focus back onto side effects. In this regard, he named Diasone as the 'best tolerated sulfone', but acknowledged that more conclusive claims could not yet be made given the drug's estimated application period of two to three years. ${ }^{180}$

When Naegele left the hospital in 1952, Schweitzer recorded his doctor's recommendations and observations in his notebook. The conclusions of both men reveal that they weighted efficacy less heavily than side effects when evaluating a drug's potential. They declared Promin to be the most efficacious drug, but also the one with the most regular side effects, and recommended using it only when other drugs did not work. Both still considered Diasone to be the drug with the fewest side effects, even when taken in very high doses. ${ }^{181}$ Schweitzer explained to Robert Weiss that 'Diasone has proved to be the most useful, albeit slow acting remedy because of its relative harmlessness'. However, Schweitzer was aware that there were less expensive alternatives and expressed his intention to conduct further trials. ${ }^{182}$

Cost was a constant concern for Schweitzer. Later in 1952, Dr. Emeric Percy, who took over from Naegele, updated Schweitzer on 'new ways in leprosy therapy'. Unlike Naegele, Percy trialed chaulmoogra again, while the other compounds remain unknown. Schweitzer did not reproduce these findings in detail, and Percy's letters have not survived, but the results Percy had summarized pleased the hospital director. ${ }^{183}$ These promised a reduction in side effects and an end to the 'ghost of anemia', and would enable the doctors to return to using the 'cheaper Disulone', Schweitzer's initial preference. Percy's trials also confirmed Schweitzer's belief that 'chaulmoogra doesn't lose its significance next to the sulfones', ${ }^{184}$ a conviction he had already professed in his letter to Weiss some three years earlier, before Naegele had started trialing sulfones.

In 1953, Schweitzer once again listed detailed guidelines on the treatment of leprosy in his notebook. These were a combination of Naegele's and Percy's

after which first effects occur on a regular basis, after "primary deteriorations", which also occur on a regular basis, have abated following the first or second course of treatment'.

179 Naegele to Schweitzer, 8 June 1951, AMs.

180 Naegele, 'Streiflichter aus Lambarene. 1951 III. Um die Lepra', AMs, 3-4.

181 See the notebook 'Medizinische Notizen, Albert Schweitzer Lambarene 1953', 41ff, AMS.

182 Schweitzer to Weiss, 8 January 1952, AMs.

183 Schweitzer to Percy, 14 August 1952, AMS.

184 Schweitzer to Percy, 13 November 1952, AMS. 
findings, and incorporated the notable return of chaulmoogra. Under the heading 'treatment of the lepers: fundamentals', Schweitzer determined that each patient would receive a 'base therapy' with a sulfone drug, either Disulone, Diasone, or Promin. He did not stipulate how the specific drug was to be selected, but defined the subsequent procedure as follows:

Keep up this treatment if permanent improvement is shown after controls every 6 weeks. If there is stagnation of various months, then add injections of Promin or Disulone Retard or both, and in any case chaulmoogra. If that doesn't help then change fundamentally. ${ }^{185}$

The many 'ifs', 'ors', 'whens' and 'thens' in this excerpt reveal the hospital's adoption of the case-to-case approach that Naegele had already recommended after his first trials and which would be implemented more frequently in the following years. In a jointly written document entitled 'medical work at the Hospital', Percy and Schweitzer insisted in 1955 that 'more and more we expand the principle that leprosy must be treated individually and not schematically. This means that not only the drug itself, but also the dosage has to be adapted individually'. ${ }^{186}$ As a result of this policy, a large variety of sulfone drugs were used at the hospital.

In 1956, Schweitzer wrote to Bernoulli again, disclosing further information on the properties that a drug needed to possess in order to be prescribed at his hospital. The pharmacologist had claimed in the eighth edition of the pharmaceutical encyclopedia he co-edited, published in 1955, that Promin was no longer used. As in the case of emetine, Schweitzer invoked his experience to correct Bernoulli. 'But for those working with leprosy that verdict is not valid. For those, Promin remains one of the best, if not the best, remedy against leprosy!' he wrote. ${ }^{187}$ According to Schweitzer, Promin's main disadvantage was that it had to be injected daily. This was practically impossible in most parts of the world in which leprosy was prevalent, where there were typically few medical practitioners as well as a trend towards the abandonment of the asylum model due to financial considerations. This letter is a rare instance in which Schweitzer or his staff discussed the preferences of their patients. He claimed that

185 See the notebook 'Medizinische Notizen, Albert Schweitzer Lambarene 1953', 33f, AMs.

186 As the following page of this document is missing, there are no further details on the treatment of leprosy to be found. It is unclear if the document was written for internal use or public discussion. It is kept among Emeric Percy's correspondence at the AMs.

187 Schweitzer to Bernoulli, 20 October 1956, AMs. 
My patients keep asking me to treat them with Promin. The reason for this is that it is administered intravenously, meaning that there is no risk of abscesses, which often occur with even the best intramuscular techniques. ${ }^{188}$

Schweitzer did not disclose that the hospital's favored leprosy medication, Diasone, was administered orally, and not by injection, and that the doctors had found it to have the fewest side effects of all sulfone drugs. Instead, he focused on Promin's supposedly superior efficacy, but claimed, somewhat contradictorily, that patients preferred it because of its comparatively few side effects, while his doctors had concluded that the drug had many of them.

Such confident statements notwithstanding, trials with further leprosy drugs continued at the hospital. A trial-and-error approach was imposed on patients when their condition would not improve, as a report on Leprosan trials illustrates. ${ }^{189}$ Starting in October 1956, twelve patients received this new Austrian sulfone brand. Eight of these patients had lived at the hospital for five years or more, during which time their condition had not improved despite having been given as many as seven different leprosy drugs during the course of their stay, not including those administered to treat secondary afflictions such as skin infections. It is not known whether these were the only patients whose conditions did not improve, which seems unlikely; neither is it possible to reconstruct the criteria by which they were selected to receive Leprosan. Besides one exception who suffered 'severe reactions', the other eleven patients showed promising signs after taking the drug for five months. Although this was admitted to be too limited a trial period to deliver meaningful results, Schweitzer ordered a large quantity of Leprosan, which he classed as 'excellent'.190

This document on the Leprosan trials also illustrates that even sulfones, which were regarded as fairly efficacious, were not without alternatives (see Illustration 37). Five of the twelve patients had received an antibiotic, Citocilline, to target the bacilli. A more illuminating case, on which further details are available, was Vitamin D. The document lists one patient as having also been treated with the vitamin at some point of his or her stay.

188 Ibid.. As if the authors followed Schweitzer's suggestion, unlike in the case of emetine, they changed the entry on Promin in the next (ninth) edition of 1959. They wrote that Promin 'must, because not well tolerated int., be administered i-ven., but is a very efficacious remedy if controlled well'. Lehmann and Bernoulli, Übersicht der gebräuchlichen und neueren Arzneimittel, 330.

189 This document is entitled 'Leprosan Patienten' and dated 14 February 1958; the author is unknown. It is kept in an unnamed box at the AMs.

190 Schweitzer to Kik, 6 June 1958, AMs. I could not obtain any further useful information on Leprosan. 


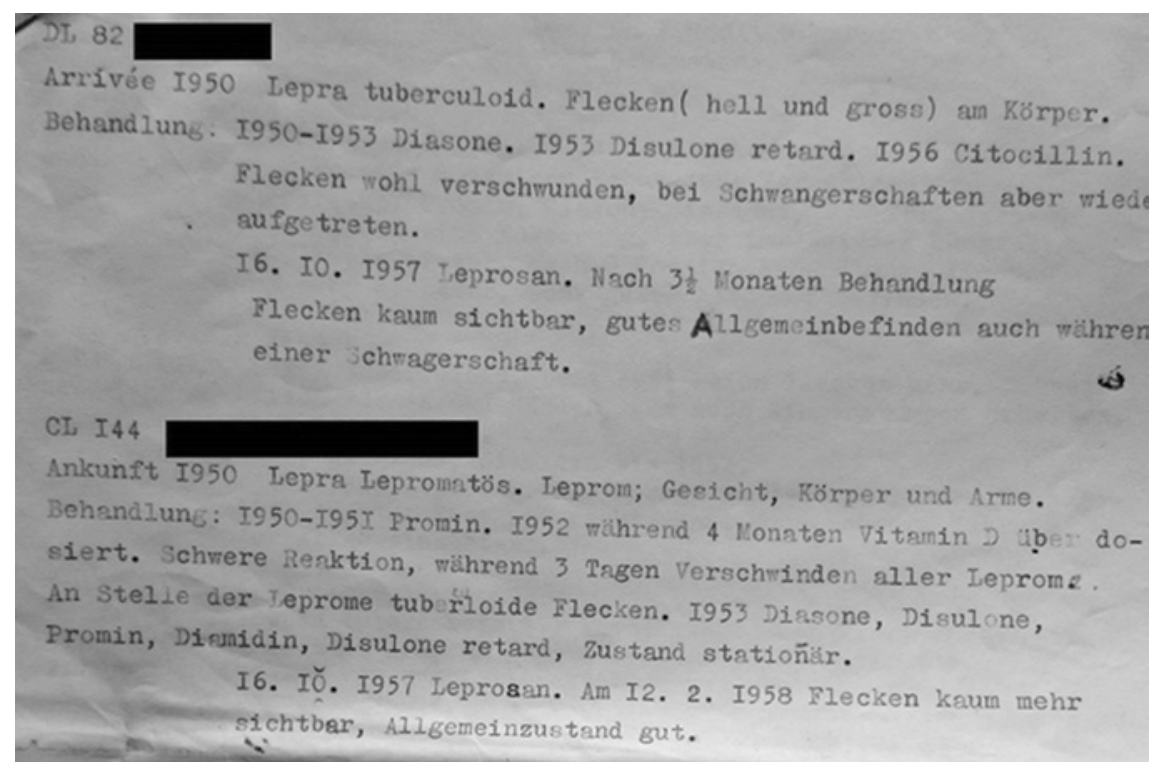

ILLUSTRATION 37 From the Leprosan trials; list of drugs that a patient had received, $195^{8}$ (C) ARChives CENTRALES Albert SCHWEITZER GUNSBACH

Naegele had noted in his 1951 report that a 'very small' number of patients had received high dosages of Vitamin $\mathrm{D}$ and that the results were 'promising'. ${ }^{191}$ The doctors soon realized, however, that the vitamin was highly problematic due to its side effects, and thus agreed to suspend testing. In 1953, Schweitzer recorded in his notebook that Vitamin D was 'too dangerous in greater quantities'; a woman who had been given ten grams per day for a period of six weeks was now in 'danger of life'. Schweitzer concluded that 'the efficacy is there, but you need to go almost to the toxic dose. ${ }^{192}$ Vitamin D and chaulmoogra - as well as Stovarsol and Jodalgin in the case of dysentery - were thus seriously considered to replace or complement an efficacious standard drug, emetine or Diasone, which had received such a reputation by a process that was by no means straightforward. In their daily practices, doctors were regularly confronted with the shortcomings of these new drugs, which they attempted to overcome via further trial-and-error tests.

The last file relating to leprosy among the archival sources, probably from 1958, is entitled 'leprosy medicaments' and was intended as a guideline for

191 Naegele, 'Streiflichter aus Lambarene. 1951 III. Um die Lepra', AMs, 3-4.

192 See the notebook 'Medizinische Notizen, Albert Schweitzer Lambarene 1953', 45f, AMs. 
prospective personnel at the hospital. ${ }^{193}$ The doctors now attempted to standardize treatment and provide an alternative for each option. As stated in the document, chaulmoogra was no longer used. Diasone had become the standard drug, with Promin prescribed to patients who did not react to Diasone, and Leprosan to those who did not respond to Promin. These sulfones were not to be given in combination with other drugs, except when a patient suffered from chronic rheumatic diseases or had a heart condition. Other diseases were always to be treated before administering sulfones. Antibiotics were considered useful in halting secondary infections and thus improving a patient's overall condition. Given the constant shifts in treatment detailed in this chapter, it is doubtful that this neatly structured treatment regime remained in place for long at the Albert Schweitzer Hospital.

\section{5 \\ Conclusion}

Leaving aside the pharmaceutical treatment methods employed there, Schweitzer's leprosy settlement represented somewhat of an anachronism. In the 1950s, at a time when French colonies were directing their efforts towards outpatient treatment, Schweitzer's leprosery operated as an open-access space where patients could bring their families and stay for an extended period of time. Contrasting with the earlier harsh treatment of dysentery patients, who were regularly forced into isolation in a locked ward, this arrangement was not only a manifestation of Schweitzer's particular socio-medical ideology and his ethics, but was also dependent on the nature of the available pharmaceuticals.

Pharmaceutical treatment of infectious diseases followed the pattern sketched out in this chapter. A single drug - chaulmoogra, emetine, or Diasone would be used as the standard treatment for a disease. However, this would often be rejected by patients, provide unsatisfactory results, or provoke adverse side effects. A range of other drugs would then be trialed as alternatives or additional treatment options. Pharmaceutical innovations promised more efficacious treatments, thereby attracting patients in greater numbers, the treatment of whom exposed the limitations of new drugs. Doctors were forced to react to this pattern by conducting trial-and-error tests with other drugs or drug combinations.

193 This document is not dated, but in all likelihood originates from 1958, when results of the Leprosan trials became known. It is kept with the file on the Leprosan trials in the same unnamed box at the AMs. 
While the laboratory or experiment metaphor might be useful for understanding scientific practices in the colonies and even the metropole, it is less applicable to the Albert Schweitzer Hospital and presumably to other hospitals with a focus on curative services. Doctors at the hospital did not seek to participate in the wider circulation of scientific knowledge; their aim was not to test whether a drug could be universally applied, nor was it to draw universally applicable conclusions from the trials that they conducted. Instead, doctors aimed to find a treatment model that was easily adaptable to their daily practices. They tested a drug's suitability for their own patients, inquiring whether a particular individual could tolerate a specific drug. Such improvised trials could be performed easily at the Albert Schweitzer Hospital, where a constant supply of a large variety of medications was available. 